\title{
Modelling the effect of temperature on the probabilistic stress-life fatigue diagram of glass fibre-polymer composites loaded in tension along the fibre direction
}

\author{
Laurent Cormier $^{1}$ and Simon Joncas ${ }^{1}$ \\ ${ }^{1}$ Department of automated manufacturing engineering, École de technologie supérieure, Canada, Contact \\ E-mail: laurent.cormier.1@etsmtl.net
}

July 7, 2017

\begin{abstract}
Predicting the fatigue performance of composites has proven to be a challenge both conceptually, due to the inherent complexity of the phenomenon, and practically, because of the resource-intensive process of fatigue testing. Moreover, mechanical behaviour of polymer matrix composites exhibits a complicated temperature dependence, making the prediction of fatigue performance under different temperatures even more complex and resource intensive. The objective of this paper is to provide a method for the prediction of fatigue life of glass-polymer composites loaded in the fibre direction at various temperatures with minimal experimental efforts. This is achieved by using a static strength degradation approach to fatigue modelling, where only two parameters (including static strength) are temperature dependent, in conjunction with relationships for these two fatigue model parameters temperature dependence. The method relies on fatigue data at a single temperature and simple static tests at different temperatures to predict the effects of temperature on the material's fatigue behaviour. The model is validated on experimental data for two unidirectional (UD) and one woven glass-epoxy composites and is found to accurately predict the effect of temperature on fatigue life of composites. A method to obtain probabilistic stress-life $(P-S-N)$ fatigue diagrams including temperature effects is also discussed. ${ }^{1}$
\end{abstract}

Keywords: Composites, glass fibre, fatigue, temperature, strength, $P-S-N$ curve.

\footnotetext{
${ }^{1}$ This is the post-peer review author's version of the paper. The final, definitive version of this paper has been published on April 24, 2017 in the Journal of Composite Materials by SAGE Publications Ltd, all rights reserved 2017. OLaurent Cormier. Original article available from https://doi .org/10.1177/ 0021998317704896
} 


\section{Introduction}

Temperature effects on the fatigue performance of composite materials have been the subject of extensive research in the past decades. Yet, it appears that a definitive approach to modelling such temperature effects on material properties and durability is still not reached. This is certainly due to the fact that composites present themselves in a wide variety of reinforcement forms and constituent natures, while being used in a broadening range of structures subject to a wide range of external solicitations and environments. A universal model for fatigue thus has to reconcile the opposite requirements of accounting for an overwhelmingly large number of situations, yet remaining tractable and requiring a minimum of experimental efforts in order to establish the values of its input parameters.

Apart from all aspects of mechanical loading (e.g. load frequency, maximum stress, mean stress, stress amplitude, load sequence, ...), thermal loading is probably one of the most important factors in determining fatigue life of composite structures. However, most of the literature is focused on the effects of high temperatures on fatigue and very little information is available on the behaviour of composites at low atmospheric temperatures, or even cryogenic temperatures. Yet, as understanding the effects of temperature on the fatigue performance of composites is an important topic for many industries (e.g. civil infrastructure, transports, wind energy), multiple modelling approaches have been explored. Some of these, mostly those dealing with the widest possible temperature ranges, are discussed below.

Early work by Sims and Gladman[1] focused on the $R=0.1$ fatigue of woven glassepoxy composite loaded in the fibre direction for temperatures ranging from $-150^{\circ} \mathrm{C}$ to $150^{\circ} \mathrm{C}$. Their results suggested that the stress-life $(S-N)$ curves at different temperatures were superimposed when the maximum cyclic stress was normalized by the static strength $\left(S_{u}\right)$ at the same temperature. Similar conclusions were also reached by Bureau and Denault[2] for bending fatigue of glass-polyester between $-40^{\circ} \mathrm{C}$ and $50^{\circ} \mathrm{C}$, although it was not the case for glass-polypropylene under the same conditions. Bureau and Denault associated this result to the thermomechanical stability (e.g. lack of a structural transition such as vitrification, melting or low temperature transitions) of polyester within the experimental temperature range. However, even for thermosetting matrix composites, such a simple behaviour is not always borne out by experiment. For example, $R=0.1$ fatigue results by Brassard[3] for UD glass-epoxy at $-40^{\circ} \mathrm{C}$ and $20^{\circ} \mathrm{C}$ show a statistically significant downward shift of the normalized fatigue curve at low temperature and normalized fatigue curves at $-40^{\circ} \mathrm{C}$ and $23^{\circ} \mathrm{C}$ for $\pm 45^{\circ}$ glass-epoxy at $R=0.1$ obtained by Cormier et al.[4] show a statistically significant change in slope parameter with temperature.

Since Arrhenius type relationships have historically been successful in modelling the effect of temperature on chemical reactions and physical processes, it seems natural that it was applied to fatigue of composites. As such, Tang et al.[5] proposed an Arrhenius type relationship to be combined with their stiffness degradation model in order to predict effects of temperature on salt water saturated glass-vinylester cross-ply laminates. In practice, the model assumes that the slope parameter of the fatigue model follows an Arrhenius type behaviour. However, even though the model was in relatively good agreement with 
experiments run at $4^{\circ} \mathrm{C}, 30^{\circ} \mathrm{C}$ and $65^{\circ} \mathrm{C}$, the Arrhenius relationship is an empirical model that is fitted a posteriori. Thus, obtaining model parameters requires experimental fatigue data at multiple temperatures.

Rotem and Nelson[6] have proposed an approach for shifting fatigue curves to account for the effect of temperature. They used a combination of two shift factors respectively applying to $S_{u}$ (or an artificial static strength given as the fatigue curve intercept with the stress axis) and to the slope of a log-linear $S-N$ curve. In general, the shift factors would need to be determined by experiments. However, for $65 \%$ volume fraction graphite-epoxy laminates, it is suggested that the slope factor would be unity if the artificial static strength was used instead of the actual $S_{u}$. For such a case, an empirical correlation between the artificial static strength shift factor and temperature was proposed. It is important to note that log-linear fatigue curves seldom fit well in both the low-cycle and high-cycle fatigue regime. In Rotem and Nelson's work, the curve was explicitly fitted to the high cycle regime.

Mivehchi and Varvani-Farahani [7] approached the problem of temperature effects on fatigue by changing the parameters of the classical power-law used to describe fatigue (log$\log$ linear $S-N$ curve) with temperature. However, even though it is documented that the best fit power-law seldom converges to $S_{u}$ (see e.g. Sutherland[8]), the assumption that it does is used in determining one of the parameters. This results in evident bias in many of the resulting predictions. Also, the model $S_{u}$ dependence on temperature is a strictly decreasing function, as opposed to the usual sigmoid behaviour. Finally, even though the model was benchmarked on thermoset polymers, it uses the polymer's melt temperature as an input. This requirement seems incompatible with such a use given that a thermoset matrix is chemically degraded before melting.

Miyano et al.[9, 10, 11] proposed an elaborated model for predicting the influence of temperature on the long-term life (creep and fatigue) of carbon-fibre composites. This model relies on a master curve approach based on experimental static, fatigue and creep results. It benefits from a broad range of applicability by being able to deal with the viscoelastic nature of carbon fibre laminates and by being able to deal with failure probabilities. However, it requires extensive material characterization in order to obtain model parameters.

Reifsnider's and his co-workers have also devised a thorough method, called the 'Critical Element Model'. This approach was developed over a period of more than twenty years, but has been synthesized by Reifsnider, Case and Duthoit[12]. The model is able to deal with the problem of fatigue at various temperatures as well as many other damage mechanisms such as creep and thermo-oxidation. The approach is based on kinetic theory and point-wise definition of stress and strength and appears to have the capacity to accurately model the evolution of strength and is possibly the closest we have been to a global solution to failure of composites under fatigue and other loading. However, it is achieved at the expense of an extremely detailed knowledge of material's properties and of their evolution (as well as the evolution of the stress-field) over time. Unfortunately, such detailed knowledge can only be gained through extensive experimental investigations.

Finally, the strength degradation model by Epaarachchi and Clausen[13] has provisions for dealing with temperature effects. However, the formulation of a function for modelling such effects was not provided and the special case of a constant parameter was developed 
in their paper.

An important aspect of the strength and stiffness of composites under combined thermal and mechanical loads is the time-dependence of the mechanical response. This in turns means that temperature and fatigue loading rates or frequency are possibly strongly interconnected and that creep-fatigue interactions are also likely.

Research on frequency effects mainly support the idea that if the temperature remains constant, an higher frequency leads to longer life.[14, 15, 16] However, since fibre reinforced polymers are often poor heat conductor, hysteretic heating can occur at relatively low frequencies (well below $10 \mathrm{~Hz}$ ).[17, 18, 19] Sun and Chan[17] proposed a model based on crack propagation in visoelastic media to predict frequency effects on fatigue life, including the effect of temperature rise. In this context, Saff[18] and Hahn and Kim[20] proposed models for estimating the temperature rise from hysteretic heating based on viscoelasticity and heat transfer equations.

Creep fatigue interaction is another effect of the time dependence of mechanical response in polymers and their composites. Crowther, Wyatt and Phillips[21] have shown that for certain materials, at low frequency, the fatigue process is dominated by creep and failure is time rather than cycle dependent. However, at higher frequency, fatigue becomes cycle dominated. This behaviour was corroborated by results from Eftekhari and Fatemi[16, 22]. The accumulation of fatigue induced creep strains was also reported by Kujawski and Eyllin[23] for $[ \pm 45]_{5 s}$ glass-epoxy composites at room temperature. Evidence of viscoelastic behaviour was also reported in Cormier et al.[4] for $[ \pm 45]_{2 s}$ glass-epoxy at $-40^{\circ} \mathrm{C}$.

It is worth noting that fatigue models by Miyano et al.[9, 10, 11] and Reifsnider et al.[12] are meant to account for viscoelastic effects while the model by Epaarachchi and Clausen[13] includes the effect of frequency under the assumption of negligible hysteretic heating. However, Guedes[24] has suggested that the linear cumulative law employed by Myiano may not fare well for complex fatigue loads or long lifetimes. An alternative model based on the work of Reifsnider's[12] strength evolution integral concept is also shown to provide better life predictions when accounting for viscoelastic effects at low stresses (long fatigue life). Also, Eftekhari and Fatemi[16, 22] used Epaarachchi and Clausen's[13] fatigue model in conjunction with a Larson-Miller type relationship to adequately model the effects of high temperature and high frequencies on neat, talc filled and short glass fibres reinforced thermoplastics.

The state of the art just presented puts forward the main limitation of current methods for assessing effects of temperature on fatigue: a requirement for extensive fatigue and viscoelastic testing. An explicit objective of the work described here is to provide a methodology that minimizes the experimental burden required to obtain model parameters. The proposed method builds on Epaarachchi and Clausen's fatigue model and extends its abilities to the prediction of probabilistic tensile fatigue curves of glass fibre-epoxy composites loaded along the fibre direction at any temperature. The proposed approach lies on the following assumptions:

- Only $S_{u}$ and one material parameter from the fatigue model are affected by temperature (T). 
- A relationship between $S_{u}$ and that material parameter exists.

- The evolution of $S_{u}$ as a function of $T$ can be modelled by a sigmoid function.

- Creep-fatigue interactions are negligible in the fibre direction .

This last assumption is perhaps the most important and warrants some additionnal discussion. It relies on Saff's work[18], which suggests that viscoelastic effects in fatigue mainly depend on matrix shear stresses. Considering that in the case of tensile loads applied in the fibre direction, this matrix shear stress is minimized, it is plausible that the effect of viscoelasticity will also be minimized. This idea is further supported by the results of Sullivan[25] and those of Brinson and Gates[26], that show creep to be mostly negligible in the fibre direction.

Together, these four assumptions allow for the prediction of fatigue curves at any temperature within a single structural transition (e.g. glass transition) provided that $S_{u}$ is known for at least four temperatures and that fatigue results are available at one temperature.

\section{Model description}

As documented by Sendeckyj[27], Degrieck and Van Paepegem[28] or Nijssen[29], many formulations have been proposed to describe the $S-N$ relationship of composites. The current work is based on a model by Epaarachchi and Clausen[13], which is presented in equations 1 and 2 . This two parameter model relies on a strength degradation rule that describes the evolution of strength with cyclic loading and agrees with the two intuitive boundary conditions of $N=1$ at $\sigma_{\max }=S_{u}$ and $N=\infty$ at $\sigma_{\max }=0$.

$$
\begin{gathered}
D / \alpha=N^{\beta}-1 \\
D=\left(\frac{S_{u}}{\sigma_{\max }}-1\right)\left(\frac{S_{u}}{\sigma_{\max }}\right)^{0.6-\psi \sin \phi} \frac{f^{\beta}}{(1-\psi)^{1.6-\psi \sin \phi}}
\end{gathered}
$$

In equation 1 and $2, \alpha$ and $\beta$ are material constants, $\sigma_{\max }$ is the maximum cyclic stress, $f$ is the loading frequency, $\phi$ is the smallest angle between the fibre direction and the loading axis and $\psi$ is defined as:

- $\psi=R$ for $-\infty<R<1$ (tension or reversed loading),

- $\psi=\frac{1}{R}$ for $1<R<\infty$ (compression).

Epaarachchi and Clausen stated that only $\alpha$ and $S_{u}$ should be functions of temperature, but did not provide relationships for $\alpha(T)$ or $S_{u}(T)$. A goal of the current work is thus to provide such relationships. However, because of the temperature-sensitive creep-fatigue interactions present in off-axis composites[23, 30, 4] - which are not accounted for in the 
current modelling approach — the analysis is limited to tensile fatigue along the materials main fibre orientation. Therefore, equation 2 simplifies to:

$$
D=\left(\frac{S_{u}}{\sigma_{\max }}-1\right)\left(\frac{S_{u}}{\sigma_{\max }}\right)^{0.6} \frac{f^{\beta}}{(1-R)^{1.6}}
$$

Then, it is seen that for a given set of $f, S_{u}, \sigma_{\max }$ and $R$, the relationship between $\sigma_{\max }$ and $N$ only depends on $\alpha$ and $\beta$. A $S-N$ curve can be obtained by plotting equation 4 over $\sigma_{\max }$.

$$
N=\left(\frac{D}{\alpha}+1\right)^{\frac{1}{\beta}}
$$

Note that according to Epaarachchi and Clausen, $\alpha$ for a given material will differ for tests run at different temperatures. However, the model assumes that a single $\alpha, \beta$ pair, ideally obtained at $R=0.1$, is required for $-\infty<R<1$.

Thus, two requirements are identified for equation 4 to provide a complete description of the $S-N$ relationship as a function of temperature. First, as $S_{u}$ is an important model parameter and is affected by temperature, a methodology for providing a continuous description of $S_{u}(T)$ is needed. Second, another continuous relationship for $\alpha(T)$ is required. The proposed forms for these two relationships are discussed next.

\section{1 $S_{u}(T)$ relationship}

Several approaches for predicting temperature effects on $S_{u}$ were proposed in the past, mainly to account for the influence of high temperatures. Possibly the best known is Chamis's[31] empirical relationship for estimating matrix properties as a function of temperature and absorbed moisture. Used in conjunction with micromechanics models, it can provide estimates of the effect of temperature on the mechanical properties of composites. However, as stated by Christensen[32], common micromechanical models such as the rules of mixtures are limited in precision. Experimental evidences by Cormier and Joncas[33] also suggest that this formulation does not accurately predict $S_{u}$ at low temperature for UD glass-epoxy composites.

Mahieux et al.[34] demonstrated the ability of an earlier micromechanics model to predict temperature effects based on matrix properties and stress concentration around broken fibres. However, assumptions on stress transfer efficiency at the interface, fibre arrangement and load redistributions are required and the associated parameters are not easily obtained.

Cao et al.[35] suggested that for high temperatures, a modified hyperbolic tangent gave a good description of the change in ultimate strength for carbon reinforced polymer composites. However such a formulation suggests that the strength at low temperatures would be the same as that at room temperature, which is contrary to experimental evidence for glass-epoxy.[36, 37, 33, 1, 38]

Kawai et al.[39] also used a scaled hyperbolic tangent for describing the tensile and compressive strength evolution as a function of temperature for their constant life diagram 
(CLD) formulation. In this specific formulation, the hyperbolic tangent was scaled so that it would present a strength plateau either at low or at high temperature. However, as the function is symmetric, it cannot simultaneously predict both the high and low temperature behaviour. It is therefore limited to relatively narrow temperature ranges.

As far as the authors know, few formulations have explicitly been proposed for estimation of tensile strength at low temperatures apart from the micromechanics model from Dutta. [40] However, as noted in the original article, predicted and measured strengths differ by an order of magnitude. The model is also not expected to work at high temperatures because of the underlying assumption that compressive stresses due to matrix shrinkage promote fibre buckling.

Mahieux and Reifsnider[41] proposed a model based on the Weibull distribution survival function (SF) to describe the evolution of polymer modulus with temperature. The model is based on the assumption that this SF can describe the failure of secondary molecular bonds governing the polymer's stiffness. Although it was originally limited to describe the evolution of polymer stiffness as a function of temperature, Correia et al.[42] showed that the formulation also provides a relatively good fit on data for strength of composites as a function of temperature. However, Gibson et al.[43] suggest that Mahieux and Reifsnider's model tends to exhibit an excessively strong curvature in the low temperature region to accurately describe the actual strength or modulus behaviour.

Correia et al.[42] proposed an alternative to Mahieux and Reifsnider's model based on the Gompertz cumulative distribution function (CDF, with CDF $=1-\mathrm{SF})$. However, since the Gompertz CDF has an even more abrupt initial transition than Weibull's SF, the problem noted by Gibson et al.[43] is not improved on. Moreover, since it uses the CDF, the physical explanations of Mahieux and Reifsnider are not applicable.

On the other hand, the SF of the Gompertz distribution[44, 45] provides a more gradual initial transition and, as a SF, is in agreement with Mahieux and Reifsnider's hypothesis. A new formulation of $S_{u}(T)$ based on the SF of the Gompertz distribution is thus proposed (equation 5) in an effort to improve on Mahieux and Reifsnider's concept.

Gompertz's SF is a monotonically decreasing function asymptotic to one and zero. However, a lower bound at $S_{u}=0$ is not appropriate in the presence of fibres which will allow for some residual strength even for $T \gg T_{g}$ [35]. Similarly, it is possible that low temperature strength exceeds the strength at room temperature. Thence, the Gompertz SF needs to be scaled and shifted. The scaling is done through the addition of parameter $A$ that multiplies the SF while the upwards shift is simply obtained by adding a constant $S_{u}^{*}$, the lower strength asymptote (remaining strength fraction at $T \gg \Theta$ ).

$$
\frac{S_{u}}{S_{u, 0}}=A \exp \left\{-\eta\left[\exp \left(-\gamma T_{n}\right)-1\right]\right\}+S_{u}^{*},
$$

In equation $5, S_{u} / S_{u, 0}$ is the ratio of $S_{u}$ at a given temperature $T$ to $S_{u, 0}$, the static strength at $T_{0}, A$ is a global scaling parameter controlling the upper asymptote, $\eta$ is the distribution shape parameter (an indicator of the structural transition temperature $\Theta$ ), $\gamma$ is the distribution scale parameter representative of the material temperature sensitivity. The 
model also relies on a normalized temperature $T_{n}$, defined as:

$$
T_{n}=\frac{\Theta-T}{\Theta-T_{0}}
$$

in which $T_{0}$ is the reference temperature, and $\Theta$ is the structural transition temperature. Note that $T_{0}$ could be any temperature, but for a matter of convenience it will in most cases be the standard laboratory temperature. The definition of $T_{n}$ is based on two considerations. First, $\Theta$ should be representative of the structural transition temperature being considered (e.g. $T_{g}$ ) so that the inflection point of equation 5 lies close to $\Theta$. Second, the condition that $S_{u} / S_{u, 0}=1$ at $T_{n}=1$ (i.e. $T=T_{0}$ ) must be met. Based on this last condition, it is easily shown that:

$$
A=\frac{1-S_{u}^{*}}{\exp \{-\eta[\exp (-\gamma)-1]\}} .
$$

Thus, only three independent parameters $\left(\eta, \gamma\right.$ and $\left.S_{u}^{*}\right)$ remain. These parameters are obtained by fitting the model to $S_{u}$ measurements at different temperatures over the range of interest and preferably spanning on each side of $\Theta$.

Note that $T_{n}$ is an inverse indicator of $T$ when $\Theta>T_{0}$, meaning that $T_{n}<0$ for $T>\Theta$ and vice versa. As this is likely to be the most common case (i.e. for analysis at $\Theta \approx T_{g}$ ), an explicit negative sign for the $\gamma$ parameter is used in equation 5 and equation 7 , ensuring that the Gompertz SF is an increasing function of $T_{n}$. However, when dealing with low temperature fatigue, it might become more practical to set a value of $\Theta<T_{0}$ allowing for reference experiments to be run at a temperature as close to ambient as possible despite the fact that $\Theta$ might be much lower. In such a case, the negative sign before $\gamma$ in equations 5 and 7 would be omitted.

It is also worth noting that this formulation is limited to materials that exhibit a single structural transition around $\Theta$. As an example, assuming that the region of interest is around $\Theta=T_{g}$, equation 5 cannot account for the additional relaxations at the melting temperature of thermoplastic resins, at the decomposition of thermosetting polymers or for the low temperature $\beta$ or $\gamma$-transition of some matrices like those found by Sims and Gladman [1], Adams and Singh[46] or Robert and Benmokrane[47]. However, even though equation 5 cannot continuously describe multiple transitions, separate application of the formula to each region is possible.

\section{$2.2 \alpha(T)$ relationship}

Based on results from two experimental investigations on the topic of temperature effects on fatigue life of UD glass-epoxy composites - the European Upwind [37, 36] project and the Canadian Wind Energy Strategic Network (WESNet)[33, 3] - it has been determined that there is a correlation between the effects of temperature on $S_{u}$ and $\alpha$. This correlation obeys equation 8 and is shown in Figure 1.

$$
\left(\frac{S_{u}}{S_{u, 0}}\right)^{T_{n}}=\frac{\alpha}{\alpha_{0}}
$$




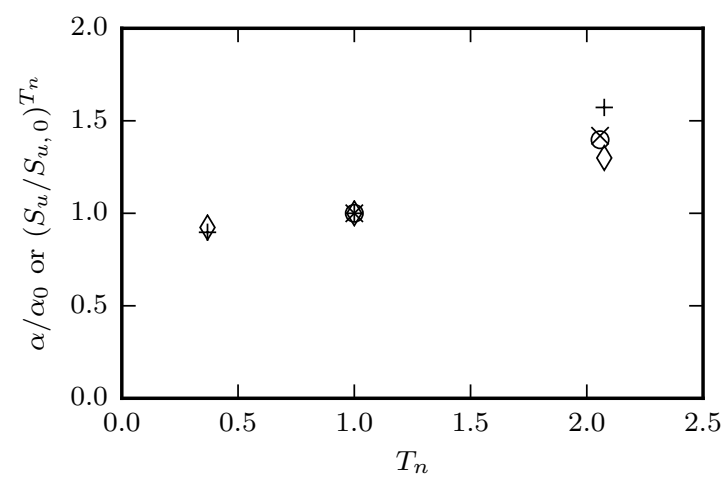

\begin{tabular}{|cl|}
\hline$\bigcirc$ & WESNet, $\left(S_{u} / S_{u, 0}\right)^{T_{n}}$ \\
& $\left(\Theta=82.6^{\circ} \mathrm{C}, T_{0}=23^{\circ} \mathrm{C}\right)$ \\
$\diamond$ & Upwind, $\left(S_{u} / S_{u, 0}\right)^{T_{n}}$ \\
& $\left(\Theta=81.6^{\circ} \mathrm{C}, T_{0}=23^{\circ} \mathrm{C}\right)$ \\
$\times$ & WESNet, $\alpha / \alpha_{0}$ \\
+ & Upwind, $\alpha / \alpha_{0}$ \\
\hline
\end{tabular}

Figure 1: Correlation between $\alpha / \alpha_{0}$ and $\left(\mathrm{Su} / S_{u, 0}\right)^{T_{n}}$.

It is believed that the empirical relationship of equation 8 should remain valid as long as the following conditions are met. First, the specimen is not subject to excessive internal heat generation due to hysteresis. Second, the failure modes for static and fatigue are and remain the same despite the temperature change. Third, the temperature change does not result in mechanical or chemical deterioration of the constituents due to internal stresses or thermo-oxidation.

Because of these requirements, it is desirable that quasi-static strength data are available beyond the temperature range of interest to ascertain the fact that a single transition is observed. In the case of multiple transitions, a full description of the material behaviour can still be obtained at the expense of fatigue tests at one temperature within each transition.

\section{Materials and methods}

The model predictions are compared to experimental results from four sources. The first two sources are recent and independent research programmes including quasi-static and fatigue test campaigns on UD glass-epoxy composites at different temperatures: the European Upwind [37, 36] project and the Canadian WESNet programme[33, 3]. The third source is an older data set by Sims and Gladman[1]. The last is Cao et al.'s[35]. The static relationship of equation 5 is validated on Upwind's, Sims and Gladman's and Cao et al.'s datasets. Fatigue predictions are compared to results from Upwind, WESNet and Sims and Gladman. These results are used because they cover a wide temperature range above and below ambient and include a variety of glass-fibre fabric types.

The data set by Sims and Gladman includes quasi-static and $R=0.1$ fatigue data for 
Table 1: Description of materials

\begin{tabular}{lll}
\hline & \multicolumn{2}{c}{ Research programme } \\
\cline { 2 - 3 } Material property & Upwind & WESNet \\
\hline Fibre form & $963 \mathrm{~g} / \mathrm{m}^{2}$ stitched unidirectional E-glass & $605 \mathrm{~g} / \mathrm{m}^{2}$ woven unidirectional E-glass \\
Warp roving & $864 \mathrm{~g} / \mathrm{m}^{2}, 2400$ tex glass & $594 \mathrm{~g} / \mathrm{m}^{2}, 1100$ tex E-glass \\
Primary fill & $40 \mathrm{~g} / \mathrm{m}^{2}, 200$ tex glass & $11 \mathrm{~g} / \mathrm{m}^{2}, 134$ tex E-glass \\
Secondary fill & $41 \mathrm{~g} / \mathrm{m}^{2}, 61$ tex glass & $60 \mathrm{tex}^{b}$ \\
Stitching & $18 \mathrm{~g} / \mathrm{m}^{2}$ polyethersulfone & None \\
Resin & Bisphenol A epichlorohydrin epoxy & Diglycidyl-ether of bisphenol-A epoxy \\
Hardener & Mixture of polyamines & Amine \\
Glass transition temperature & $81.6^{\circ} \mathrm{C}^{c}$ & $82.6^{\circ} \mathrm{C}^{d}$ \\
Fibre volume fraction $\left(v_{f}\right)$ & 0.48 & 0.55 \\
Ply sequence & {$\left[0_{4}\right]^{e}$} & {$\left[0_{3}\right]$} \\
\hline
\end{tabular}

${ }^{a}$ Combined primary and secondary fill areal weight

${ }^{b}$ Glass reinforced thermoplastic woven and fused to the warp fibres for every two primary fill rovings.

${ }^{c}$ As measured by differential scanning calorimetry on 12 specimens.

${ }^{d}$ Matrix property from resin manufacturer technical data sheet.

${ }^{e}$ As each ply is not balanced, fill fibres are alternatively placed facing out/in/in/out to ensure laminate symmetry and balance.

$3.2 \mathrm{~mm}$ thick hot-pressed fine weave glass-epoxy laminates of $v_{f}=0.45$. Tests were all performed along the main roving of the laminate. Quasi-static and cyclic tests were all performed under load control at a stress rate of $1250 \mathrm{MPa} \mathrm{s}^{-1}$. Tests were performed at temperatures of $-150^{\circ} \mathrm{C}$ to $150^{\circ} \mathrm{C}$. However, as thermo-oxidation of the matrix was reported at $150^{\circ} \mathrm{C}$, results at that temperature will not be considered here. It is also worth noting that Sims and Gladman only provide average fatigue lives at each load level and do not give information about the fatigue results dispersion. However, a $3 \%$ coefficient of variation is reported on $S_{u}$ at all temperatures.

Cao et al.'s[35] provides $S_{u}$ data at temperatures ranging from $20^{\circ} \mathrm{C}$ to $120^{\circ} \mathrm{C}$ for UD carbon-fibre composites with two different epoxy formulations, namely FR-E3P and SX-435 resins. These composites are later identified as CFRP1 for the composite using FR-E3P resin and CFRP2 for that using SX-435 resin.

Details of experimental procedures for Upwind and WESNet as well as computational approaches are given below.

\subsection{Experimental}

For Upwind and WESNet, load controlled fatigue experiments at $R=0.1$ and displacement controlled quasi-static tests were performed. All experiments were carried out on servohydraulic test frames. However, each test campaign had some peculiarities. Materials details for both programmes are given in Table 1. 


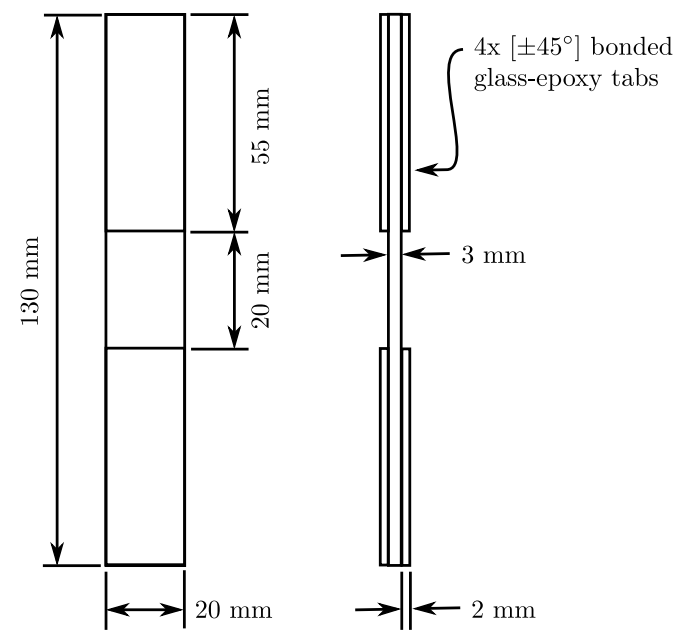

Figure 2: OptiMAT Blade Project R08 specimen geometry.

In the Upwind programme, tests were performed at $-40^{\circ} \mathrm{C}, 23^{\circ} \mathrm{C}$ and $60^{\circ} \mathrm{C}$. At least six specimens were tested at each temperature for quasi-static evaluation. Fatigue experiments were conducted at two load levels with a minimum of five specimens tested at each level. The fatigue test frequency changed according to the load level in order to maintain an approximately constant strain energy rate as described in [37, 48, 49]. This precaution ensured that if any internal heat generation or cyclic creep build-up occurred, it would remain relatively uniform over all test conditions, minimizing the risk that strain rate or hysteretic effects be confounded with temperature effects. Control over the test temperature was achieved by circulating air from an external environmental chamber through the insulated test enclosure. Specimens were left standing in the test environment for a minimum of 15 minutes before the start of a test. The air and specimen surface temperature were both monitored during the tests.

A non-standard test specimen geometry was used. The geometry is taken from the OptiMAT Blade Project and the associated OptiDAT database [50], which used a common specimen geometry for tension and compression fatigue. This choice was made in order to eliminate potential uncertainties related to geometric effects. This geometry, referred to as R08, was used for Upwind in order to maintain consistency with results from the earlier OptiMAT Blade Project. The R08 specimen geometry is shown in Figure 2. End tabs are bonded with epoxy paste.

Laminates were manufactured at the Knowledge Centre Wind Turbine Materials and Constructions (WMC). They were vacuum infused under rigid tooling and cured at atmospheric pressure to minimize void volume. The lower and upper mould plates were bolted together with shims inserted in between the plates to ensure a predetermined spacing based on the target $v_{f}$ and the areal weight of the fabric. The tooling and resin were preheated to $30^{\circ} \mathrm{C}$ prior to infusion. The infusion was performed at $30^{\circ} \mathrm{C}$ under full vacuum. After 
infusion, the inlet and outlet were closed and the pressure set back to ambient. The temperature was then increased to $50^{\circ} \mathrm{C}$ at a rate of $1{ }^{\circ} \mathrm{C} /$ minute and kept at $50^{\circ} \mathrm{C}$ for three hours. After the first temperature dwell period, the temperature was raised to $70^{\circ} \mathrm{C}$ at a rate of $1{ }^{\circ} \mathrm{C} /$ minute and remained at this temperature for ten hours. The final cooling phase was uncontrolled. Specimens were wet-cut using a circular diamond blade.

For the WESNet programme, quasi-static and fatigue tests were performed at $-40^{\circ} \mathrm{C}$ and $23^{\circ} \mathrm{C}$ on specimens that were previously vacuum dried. Quasi-static tests were performed in accordance to ASTM D 3039 [51] on a minimum of five specimens per temperature condition. Fatigue tests under each temperature conditions were conducted on a minimum of six specimens distributed over three stress levels. Fatigue tests were performed at a constant frequency of $5 \mathrm{~Hz}$ which was verified to limit the specimen hysteretic heating to about two degrees Celsius as measured on the specimen surface. Room temperature tests were performed under laboratory ambient conditions while for tests at $-40^{\circ} \mathrm{C}$, the specimen was installed in a test chamber equipped with a liquid nitrogen cooling system. Air temperature around the specimen was monitored and controlled via a feedback loop controller.

For WESNet, the specimen geometry was as per ASTM D 3039 for UD composites. Bevelled tabs made of $2 \mathrm{~mm}$ thick $\pm 45^{\circ}$ glass-epoxy composites were bonded using epoxy paste adhesive. The test specimens were resin infused at full vacuum. However, once the laminate was fully impregnated with resin, the vacuum level was reduced to $3 / 4$ bar for the duration of the consolidation. This last step was meant to reduce the thickness gradient along the plate length and to minimize the volume of any remaining entrapped gases. Specimens were machined on a numerically controlled milling machine equipped with a polycrystalline diamond coated end mill and their edges were polished on water lubricated metallography polishing benches with abrasives up to 600 grit.

\subsection{Computational approach}

Model parameters for equation 5 are obtained by a non-linear regression using Python 2 SciPy 0.17 package optimize module's curve_fit procedure. The regressions are performed on the mean strength, but the standard deviations are also provided to the curve_fit procedure for weighting purpose. Parameters for the $S_{u}(T)$ relationship are evaluated for materials from Upwind[36], Sims and Gladman[1] and Cao et al.[35] As the WESNet[33] material was only tested at two temperatures, the data are too scarce to fit the model.

In their paper, Epaarachchi and Clausen[13] used trial and error to fit their model. In the present study, parameters $\alpha$ and $\beta$ from equation 1 are determined by using a script that symbolically solves for the slope parameter $\alpha$ and coefficient of determination $r^{2}$ as a function of $\beta$ in a linear regression of $D\left(\beta, \sigma_{\max }\right)$ on $N^{\beta}-1$. A least square regression method is used and the regression line is forced to zero. The script then iterates over a range of $\beta$ and evaluates the resulting $\alpha$ and $r^{2}$. The maximum value of $r^{2}$ is searched for and the associated $\alpha$ and $\beta$ set is given as the solution. Values of coefficients $\alpha$ and $\beta$ at reference temperature $T_{0}$ (denoted as $\alpha_{0}$ and $\beta_{0}$ ) are first found using the aforementioned script. For all other temperatures, the condition $\beta=\beta_{0}$ is imposed and $\alpha$ is evaluated according to 
equation 8 (further identified as $\alpha_{\text {model }}$ ).

The quality of fit of curves predicted using $\alpha_{\text {model }}$ and $\beta_{0}$ is evaluated using the coefficient of determination, further denoted as $r_{\text {model }}^{2}$. In order to provide a comparative basis, fatigue curves are also fitted on data at each temperature using the regression script with $\beta=\beta_{0}$. The output of those regression is further labelled as $\alpha_{\text {reg }}$ and $r_{\text {reg. }}^{2}$.

For comparison purpose, the fatigue model is fitted using both the measured static strength $\left(S_{\mathrm{u} \text {, measured }}\right)$ and the modelled static strength $\left(S_{\mathrm{u} \text {, model }}\right)$. - - predicted from equation 5 - for all datasets except WESNet's. In this case experimental strength measurements are used.

Finally, in cases where the frequency used for fatigue tests under different load or temperature conditions is not constant, an average frequency is used in equation 4 and kept the same for all conditions. This is consistent with the approach used by Epaarachchi and Clausen (equation 1).

\section{Results and discussion}

\section{1 $S_{u}(T)$ predictions for Cao et al.'s[35] material}

As a demonstration of the ability of equation 5 to describe the evolution of $S_{u}(T)$, the model has been tested on data for two UD carbon fibre-epoxy composites from Cao et al.[35] For both fits, a reference temperature of $T_{0}=35^{\circ} \mathrm{C}$ was used. The structural transition temperature used was the midpoint of the reported $T_{g}$ range. Thus, $\Theta=49^{\circ} \mathrm{C}$ and $\Theta=54^{\circ} \mathrm{C}$ are respectively used for modelling the behaviour of CFRP1 and CFRP2 materials.

Estimates of model parameters are $A=0.1339, \eta=0.99, \gamma=1.53$ and $S_{u}^{*}=0.71$ for CFRP1 and $A=0.1841$, et $a=0.54, \gamma=2.63$ and $S_{u}^{*}=0.70$ for CFRP2. The model predictions and data are shown in Figure 3. It is seen that equation 5 provides a very good description of the effect of temperature on the strength of UD composites within the temperature range considered.

\section{2 $S_{u}(T)$ and fatigue life predictions for Upwind's[37, 36] material}

The static model (equation 5) is applied to data from Upwind at temperatures of $-40^{\circ} \mathrm{C}$, $23^{\circ} \mathrm{C}$ and $60^{\circ} \mathrm{C}$. In the following application, $T_{0}=23^{\circ} \mathrm{C}$ and the laminates $T_{g}=81.6^{\circ} \mathrm{C}$ is taken for $\Theta$. As $S_{u}$ data are only available for two temperatures away from $T_{0}$, a further hypothesis is needed to fit equation 5. Based on results for UD carbon-epoxy tested above $T_{g}$ published by Cao et al. [35] used previously, it is seen that a lower strength plateau is found around $2 S_{u} / 3$. It is thus assumed that for the composite system used for Upwind, a similar plateau is found, imposing $S_{u}^{*}=2 / 3$. Other parameters are then found to be $A=0.0364, \eta=2.60$ and $\gamma=1.88$. Figure 4 shows the resulting strength ratio as a function of temperature.

The fatigue model parameters as found by regression and as per equation 8 are given in Table 2. The resulting $S-N$ curves are shown in Figure 5, where the solid line represents 


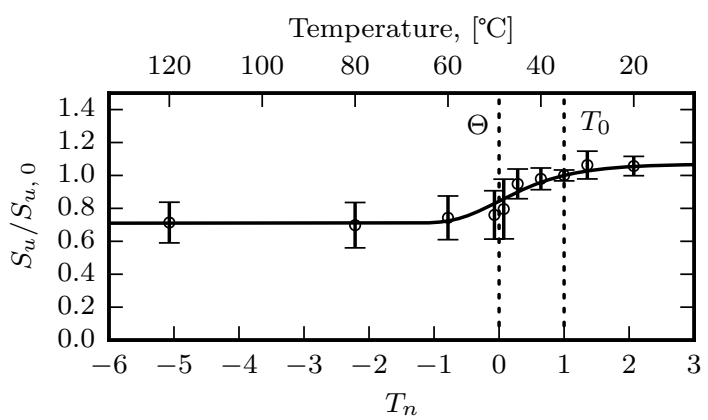

Temperature, $\left[{ }^{\circ} \mathrm{C}\right.$

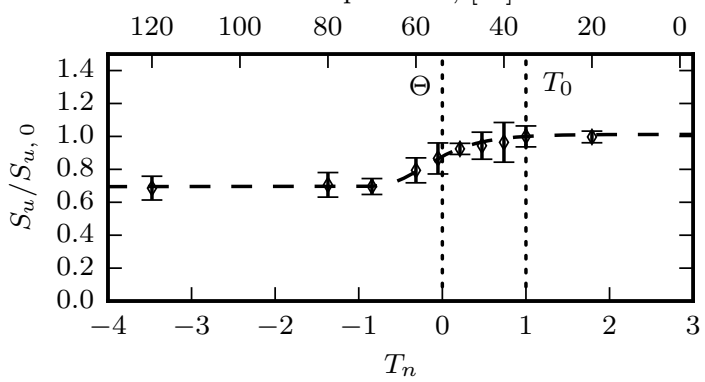

$$
\begin{aligned}
& \text { Model, CFRP1 } \\
& \left(A=0.1339, \eta=0.99, \gamma=1.53, S_{u}^{*}=0.71\right) \\
& \Phi \operatorname{CFRP} 1\left(\Theta=49.0^{\circ} \mathrm{C}, T_{0}=35.0^{\circ} \mathrm{C}\right) \\
& \text { Model, CFRP2 } \\
& \text { - - }\left(A=0.1841, \eta=0.54, \gamma=2.63, S_{u}^{*}=0.70\right) \\
& \text { 王 } \operatorname{CFRP} 2\left(\Theta=54.0^{\circ} \mathrm{C}, T_{0}=35.0^{\circ} \mathrm{C}\right)
\end{aligned}
$$

Figure 3: Prediction of strength as a function of temperature by equation 5 for Cao et al.'s[35] materials. 


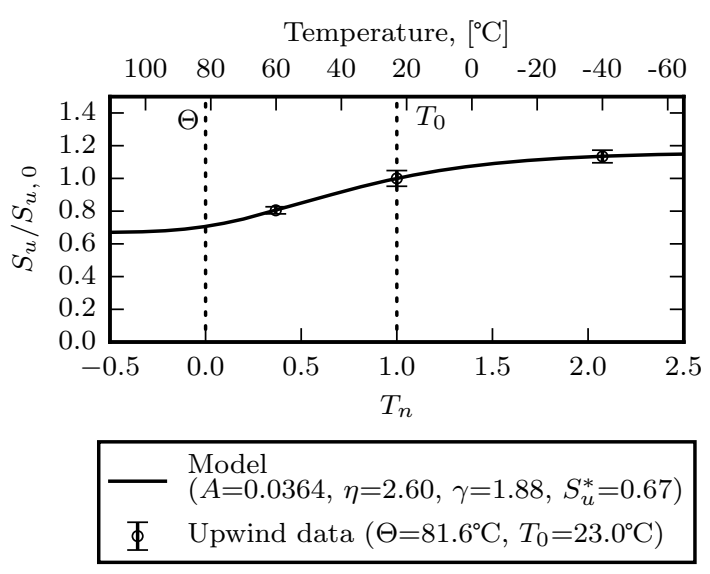

Figure 4: Prediction of strength as a function of temperature by equation 5 for Upwind's material.

the curve at $T_{0}$ and the dashed lines are predicted using $S_{\mathrm{u} \text {, model }}$ and $\alpha_{\text {model }}$ for the relevant temperature.

It is worth stressing that in Figure 5 as well as in all further $S-N$ curves provided, only the fatigue data at $T_{0}$ is used in the prediction while data points at other temperatures are only provided to illustrate the predictive capability of the proposed model.

As can be seen from Figure 5, the fit of the $S-N$ curve is very good for all temperatures.

\subsection{Fatigue life predictions for WESNet's[33, 3] material}

Additional validation of the fatigue model is provided by comparing the predicted $S-N$ curve against experimental data at $-40^{\circ} \mathrm{C}$ from the WESNet programme. The interest of this data set lies in the fact that - as was the case for Upwind - although quasi-static tests resulted in a substantial strength increase from $23^{\circ} \mathrm{C}$ to $-40^{\circ} \mathrm{C}$, the fatigue life in the high cycle regime was not significantly affected. However, the fibre architecture of the WESNet and Upwind laminates were quite different. The ability of the model to deal with such behaviour is therefore tested and a comparison of the resulting model parameters will be possible.

The $\alpha$ and $\beta$ parameters obtained by regression and with the proposed model are given in Table 3, while the baseline and predicted $S-N$ curves are shown in Figure 6 . This figure shows that the baseline and predicted $S-N$ curves are in acceptable agreement with the data. Nonetheless, it is seen that at $23^{\circ} \mathrm{C}$, the $S-N$ curve does not agree as well with the data as in previous cases. This is corroborated by the lower $r^{2}$ of 0.873 . The broad scatter at low loads combined with the usual assumption of constant standard deviation used in the regression certainly contributed to the lesser fit. Yet, this latter assumption suggests that the curve should still be representative while the data could be biased at higher loads due to the low number of experiments. Considering these limitations of the WESNet data and the good fit of predictions at $-40^{\circ} \mathrm{C}$, the model results appear acceptable. 
Table 2: Fatigue model parameters for Upwind's $R=0.1$ data.

\begin{tabular}{lllllllll}
\hline \multicolumn{10}{c}{ Estimates based on measured static strength } \\
\hline Temperature & $T_{n}$ & $\alpha_{\text {reg }}$ & $\beta$ & $r_{\text {reg }}^{2}$ & $\begin{array}{l}S_{\mathrm{u}, \text { measured }} \\
\left(S_{u} / S_{u, 0}\right)^{T_{n}}\end{array}$ & $\alpha_{\text {model }}$ & $r_{\text {model }}^{2}$ \\
${ }^{\circ} \mathrm{C}$ & - & - & - & - & $\mathrm{MPa}$ & - & - & - \\
\hline-40 & 2.08 & 0.565 & 0.197 & 0.987 & 1038 & 1.299 & 0.456 & 0.925 \\
23 & 1.00 & 0.351 & 0.197 & 0.966 & 915 & 1.000 & 0.351 & 0.966 \\
60 & 0.37 & 0.325 & 0.197 & 0.934 & 737 & 0.924 & 0.324 & 0.933 \\
\hline
\end{tabular}

Estimates based on modelled static strength

\begin{tabular}{|c|c|c|c|c|c|c|c|c|}
\hline $\begin{array}{l}\text { Temperature } \\
{ }^{\circ} \mathrm{C}\end{array}$ & $\begin{array}{l}T_{n} \\
-\end{array}$ & $\begin{array}{l}\alpha_{\text {reg }} \\
-\end{array}$ & $\begin{array}{l}\beta \\
-\end{array}$ & $\begin{array}{l}r_{\text {reg }}^{2} \\
-\end{array}$ & $\begin{array}{l}S_{\mathrm{u}, \text { model }} \\
\mathrm{MPa}\end{array}$ & $\begin{array}{l}\left(S_{u} / S_{u, 0}\right)^{T_{n}} \\
-\end{array}$ & $\begin{array}{l}\alpha_{\text {model }} \\
-\end{array}$ & $\begin{array}{l}r_{\text {model }}^{2} \\
-\end{array}$ \\
\hline-40 & 2.08 & 0.566 & 0.197 & 0.987 & 1039 & 1.302 & 0.457 & 0.924 \\
\hline 23 & 1.00 & 0.351 & 0.197 & 0.966 & 915 & 1.000 & 0.351 & 0.966 \\
\hline 60 & 0.37 & 0.323 & 0.197 & 0.934 & 735 & 0.922 & 0.324 & 0.934 \\
\hline
\end{tabular}

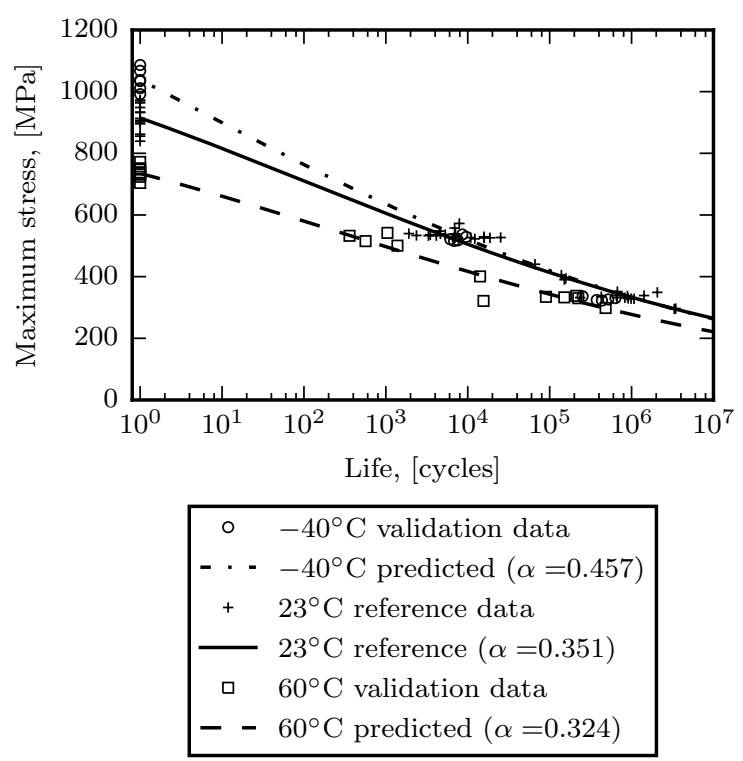

Figure 5: Predicted $S-N$ curves at different temperatures for $U p w i n d$ 's material.

Table 3: Fatigue model parameters for WESNet's $R=0.1$ data.

\begin{tabular}{|c|c|c|c|c|c|c|c|c|}
\hline Temperature & $T_{n}$ & $\alpha_{\text {reg }}$ & $\beta$ & $r_{\text {reg }}^{2}$ & $S_{u}$ & $\left(S_{u} / S_{u, 0}\right)^{T_{n}}$ & $\alpha_{\text {model }}$ & $r_{\text {model }}^{2}$ \\
\hline${ }^{\circ} \mathrm{C}$ & - & - & - & - & $\mathrm{MPa}$ & - & - & - \\
\hline-40 & 2.06 & 0.772 & 0.234 & 0.981 & 1232 & 1.398 & 0.761 & 0.979 \\
\hline 23 & 1.00 & 0.544 & 0.234 & 0.873 & 1047 & 1.000 & 0.544 & 0.873 \\
\hline
\end{tabular}




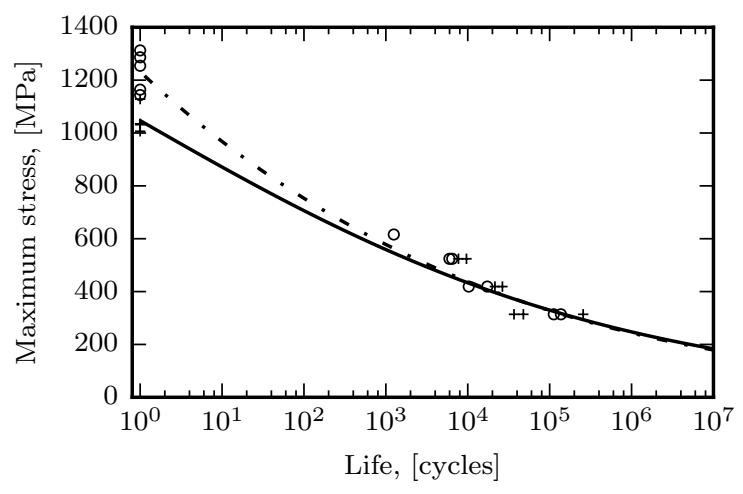

$$
\begin{array}{|cl|}
\hline \circ & -40^{\circ} \mathrm{C} \text { validation data } \\
-\cdots & -40^{\circ} \mathrm{C} \text { predicted }(\alpha=0.761) \\
+ & 23^{\circ} \mathrm{C} \text { reference data } \\
- & 23^{\circ} \mathrm{C} \text { reference }(\alpha=0.544)
\end{array}
$$

Figure 6: Predicted $S-N$ curves at different temperatures for WESNet's material.

As noted earlier, although the fibre architecture used in WESNet and Upwind differed substantially, the same overall behaviour was observed in static and fatigue. The resulting model parameters are also comparable for both cases, although WESNet's material appears to be somewhat more fatigue sensitive as suggested by the stronger curvature of the $S-N$ curves.

\section{4 $S_{u}(T)$ and fatigue life predictions for Sims and Gladman's[1] ma- terial}

In previous validation exercises, the model was tested against results for UD laminates within relatively narrow temperature ranges. It will now be tested against data from tests on woven laminates over a broader temperature range including two transition regions (as shown by the inversion of curvature around $25^{\circ} \mathrm{C}$ in Figure 7). Application of both the static and fatigue models to the two distinct regions is required and the predictive capacity within each transition region is verified.

In a first time, the ability of equation 5 to describe the evolution of $S_{u}$ as a function of temperature within both regions is tested and the best fits obtained are shown in Figure 8. It is seen that within each transition, the model is very accurate, with the curve fitting easily within one standard deviation.

As a second test, the applicability of the empirical correlation of equation 8 for the prediction of $\alpha$ is verified. Two fits by equation 8 are required because the data spans two structural transitions. The correlation between $\alpha_{\text {reg }}$ and $\alpha_{\text {model }}$ is shown in Figure 9 for each of the two fits. The first fit uses $\Theta_{1}=-100^{\circ} \mathrm{C}$ and $T_{0,1}=-20^{\circ} \mathrm{C}$ (low temperature transition) and the second is based on $\Theta_{2}=50^{\circ} \mathrm{C}$ and $T_{0,2}=23^{\circ} \mathrm{C}$ (high temperature or glass transition). It is seen that the correlation is quite good within the glass transition 


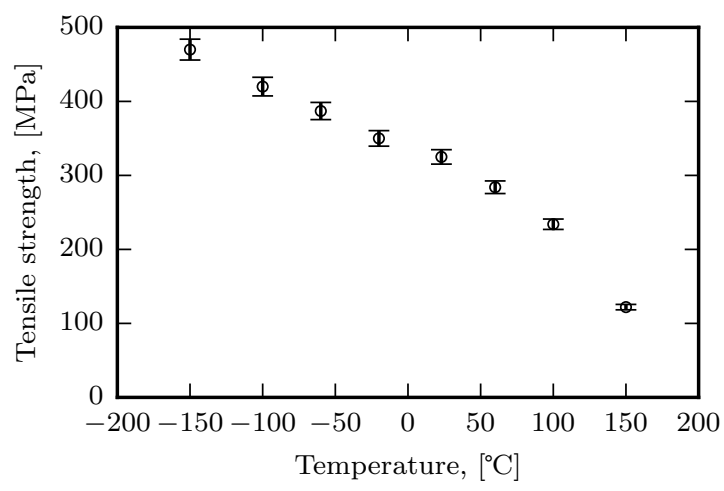

Figure 7: Tensile static strength as a function of temperature (Sims and Gladman [1]).

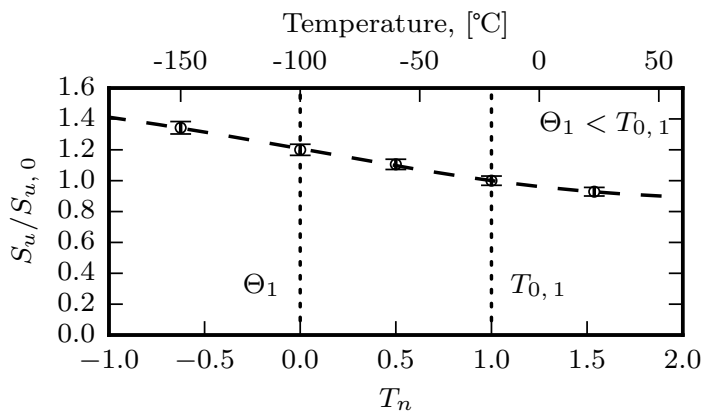

Temperature, $\left[{ }^{\circ} \mathrm{C}\right]$

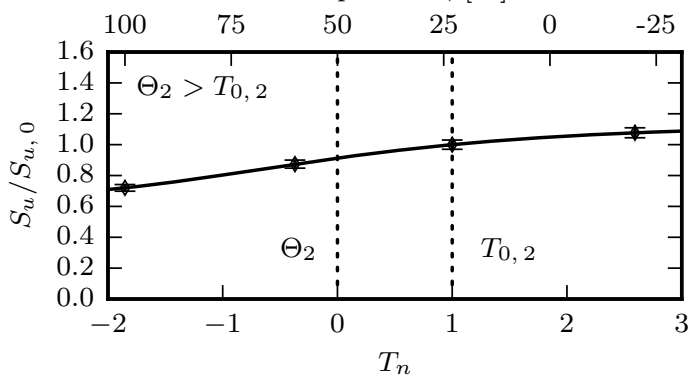

$$
\begin{array}{|c|l}
\hline \text { - } & \begin{array}{l}
\text { Low temperature fit } \\
\left(A=0.3274, \eta=0.94, \gamma=0.72, S_{u}^{*}=0.88\right)
\end{array} \\
\Phi & \left.\begin{array}{l}
\text { Experimental } \\
\left(\Theta_{1}=-100^{\circ} \mathrm{C}, T_{0}, 1\right.
\end{array}=-20^{\circ} \mathrm{C}\right) \\
& \begin{array}{l}
\text { High temperature fit } \\
\left(A=0.2487, \eta=0.61, \gamma=0.67, S_{u}^{*}=0.66\right)
\end{array} \\
& \begin{array}{l}
\text { Experimental } \\
\left(\Theta_{2}=50^{\circ} \mathrm{C}, T_{0,2}=23^{\circ} \mathrm{C}\right)
\end{array}
\end{array}
$$

Figure 8: Prediction of strength as a function of temperature by equation 5 for Sims and Gladman's material. 

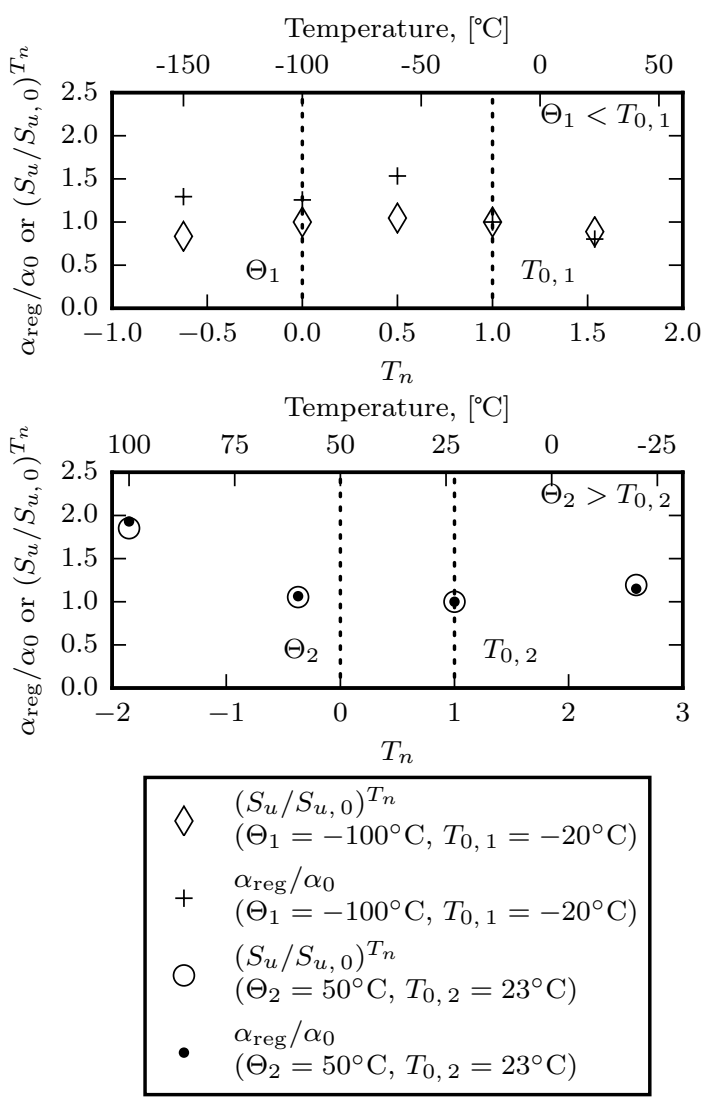

Figure 9: Correlation between $\alpha$ as found by regression and as predicted by Equation 8 for data by Sims and Gladman.

range, but slightly lesser in the low temperature transition.

Comparative values of $\alpha_{\text {reg }}$ and $\alpha_{\text {model }}$, as well as other model parameters are given in Table 4 and 5 for both transition regions. $S-N$ curves for the low temperature transition and within the glass transition region are respectively shown in Figure 10 and 11.

Results at low temperature presented in Figure 10 show a good agreement from room temperature down to $-100^{\circ} \mathrm{C}$. However, at $-150^{\circ} \mathrm{C}$, the $S-N$ curve does not fit as well, particularly in the low cycle fatigue regime. It appears that at this very low temperature, the curvature of the fatigue curve would be required to increase significantly in order to provide a good fit. This suggests the current $\beta$ estimate might not be as good at this temperature.

From Figure 11, it is seen that the agreement between the data and the $S-N$ curves is quite good for temperatures ranging from $23^{\circ} \mathrm{C}$ up to $100^{\circ} \mathrm{C}$. Therefore, for this particular laminate the proposed method is even able to predict the fatigue performance above $T_{g}$. However, at $-20^{\circ} \mathrm{C}$ the predicted life is somewhat lower than the measured life, particularly for low cycle fatigue $(N<1000)$. This suggests that the room temperature $\beta$ might not provide the best estimate of the material property at $-20^{\circ} \mathrm{C}$, a statement which is corroborated by the low temperature fit. 
Table 4: Fatigue model parameters for Sims and Gladman's $R=0.1$ data; low temperature transition $\left(\Theta_{1}=-100^{\circ} \mathrm{C} ; T_{0,1}=-20^{\circ} \mathrm{C}\right)$.

Estimates based on measured static strength

\begin{tabular}{|c|c|c|c|c|c|c|c|c|}
\hline $\begin{array}{l}\text { Temperature } \\
{ }^{\circ} \mathrm{C}\end{array}$ & $\begin{array}{l}T_{n} \\
-\end{array}$ & $\begin{array}{l}\alpha_{\text {reg }} \\
-\end{array}$ & $\begin{array}{l}\beta \\
-\end{array}$ & $\begin{array}{l}r_{\text {reg }}^{2} \\
-\end{array}$ & $\begin{array}{l}S_{\mathrm{u}, \text { measured }} \\
\mathrm{MPa}\end{array}$ & $\begin{array}{l}\left(S_{u} / S_{u, 0}\right)^{T_{n}} \\
-\end{array}$ & $\begin{array}{l}\alpha_{\text {model }} \\
-\end{array}$ & $\begin{array}{l}r_{\text {model }}^{2} \\
-\end{array}$ \\
\hline-150 & -0.63 & 0.309 & 0.267 & 0.976 & 470 & 0.831 & 0.197 & 0.721 \\
\hline-100 & 0.00 & 0.295 & 0.267 & 0.985 & 420 & 1.000 & 0.237 & 0.924 \\
\hline-60 & 0.50 & 0.371 & 0.267 & 0.994 & 387 & 1.052 & 0.249 & 0.853 \\
\hline-20 & 1.00 & 0.237 & 0.267 & 1.000 & 350 & 1.000 & 0.237 & 1.000 \\
\hline 23 & 1.54 & 0.191 & 0.267 & 0.992 & 325 & 0.895 & 0.212 & 0.980 \\
\hline
\end{tabular}

Estimates based on modelled static strength

\begin{tabular}{lllllllll}
\hline Temperature & $T_{n}$ & $\alpha_{\text {reg }}$ & $\beta$ & $r_{\text {reg }}^{2}$ & $S_{\text {u, model }}$ & $\left(S_{u} / S_{u, 0}\right)^{T_{n}}$ & $\alpha_{\text {model }}$ & $r_{\text {model }}^{2}$ \\
\hline-150 & -0.63 & 0.308 & 0.267 & 0.976 & 469 & 0.834 & 0.199 & 0.737 \\
-100 & 0.00 & 0.299 & 0.267 & 0.985 & 423 & 1.000 & 0.238 & 0.917 \\
-60 & 0.50 & 0.365 & 0.267 & 0.994 & 384 & 1.046 & 0.249 & 0.865 \\
-20 & 1.00 & 0.238 & 0.267 & 1.000 & 351 & 1.000 & 0.238 & 1.000 \\
23 & 1.54 & 0.191 & 0.267 & 0.992 & 325 & 0.888 & 0.211 & 0.981 \\
\hline
\end{tabular}

Table 5: Fatigue model parameters for Sims and Gladman's $R=0.1$ data; high temperature transition $\left(\Theta_{2}=50^{\circ} \mathrm{C} ; T_{0,2}=23^{\circ} \mathrm{C}\right)$.

Estimates based on measured static strength

\begin{tabular}{lllllllll}
\hline \multicolumn{8}{c}{ Estimates based on measured static strength } \\
\hline Temperature & $T_{n}$ & $\alpha_{\text {reg }}$ & $\beta$ & $r_{\text {reg }}^{2}$ & $\begin{array}{l}S_{\mathrm{u}, \text { model }} \\
\left(S_{u} / S_{u, 0}\right)^{T_{n}}\end{array}$ & $\alpha_{\text {model }}$ & $r_{\text {model }}^{2}$ \\
${ }^{\circ} \mathrm{C}$ & - & - & - & - & $\mathrm{MPa}$ & - & - & - \\
\hline-20 & 2.59 & 0.486 & 0.210 & 0.994 & 350 & 1.212 & 0.507 & 0.970 \\
23 & 1.00 & 0.418 & 0.210 & 0.999 & 325 & 1.000 & 0.418 & 0.999 \\
60 & -0.37 & 0.451 & 0.210 & 0.997 & 284 & 1.051 & 0.439 & 0.993 \\
100 & -1.85 & 0.814 & 0.210 & 0.989 & 234 & 1.836 & 0.768 & 0.983 \\
\hline
\end{tabular}

Estimates based on modelled static strength

\begin{tabular}{lllllllll}
\hline $\begin{array}{l}\text { Temperature } \\
{ }^{\circ} \mathrm{C}\end{array}$ & $\begin{array}{l}T_{n} \\
-\end{array}$ & $\begin{array}{l}\alpha_{\text {reg }} \\
-\end{array}$ & $\begin{array}{l}\beta \\
-\end{array}$ & $\begin{array}{l}r_{\text {reg }}^{2} \\
-20\end{array}$ & $\begin{array}{l}S_{\mathrm{u}, \text { model }} \\
\mathrm{MPa}\end{array}$ & $\begin{array}{l}\left(S_{u} / S_{u, 0}\right)^{T_{n}} \\
-\end{array}$ & $\begin{array}{l}\alpha_{\text {model }} \\
-\end{array}$ & $\begin{array}{l}r_{\text {model }}^{2} \\
-\end{array}$ \\
\hline 23 & 1.59 & 0.481 & 0.210 & 0.994 & 348 & 1.194 & 0.499 & 0.971 \\
60 & -0.37 & 0.445 & 0.210 & 0.999 & 282 & 1.047 & 0.438 & 0.991 \\
100 & -1.85 & 0.807 & 0.210 & 0.989 & 233 & 1.852 & 0.774 & 0.982 \\
\hline
\end{tabular}




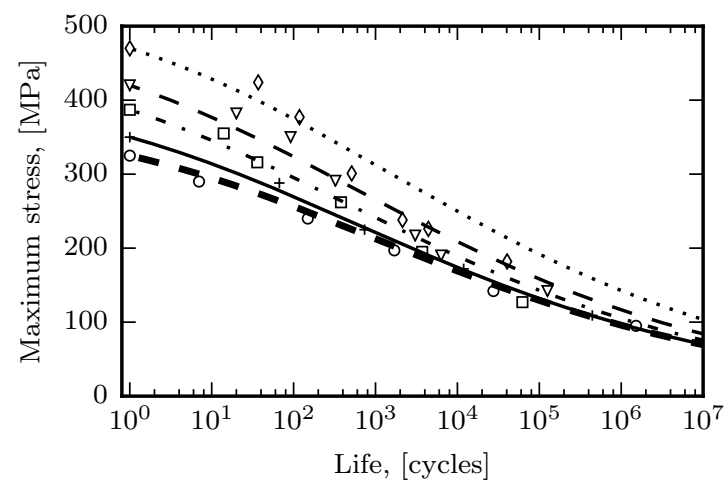

\begin{tabular}{|cl|}
\hline$\circ$ & $23^{\circ} \mathrm{C}$ validation data \\
\hline & $23^{\circ} \mathrm{C}$ predicted $(\alpha=0.211)$ \\
+ & $-20^{\circ} \mathrm{C}$ reference data \\
\hline- & $-20^{\circ} \mathrm{C}$ reference $(\alpha=0.238)$ \\
$\square$ & $-60^{\circ} \mathrm{C}$ validation data \\
$-\cdots$ & $-60^{\circ} \mathrm{C}$ predicted $(\alpha=0.249)$ \\
$\nabla$ & $-100^{\circ} \mathrm{C}$ validation data \\
- & $-\quad-100^{\circ} \mathrm{C}$ predicted $(\alpha=0.238)$ \\
$\diamond$ & $-150^{\circ} \mathrm{C}$ validation data \\
$\cdots$ & $-150^{\circ} \mathrm{C}$ predicted $(\alpha=0.199)$ \\
\hline
\end{tabular}

Figure 10: Predicted $S-N$ curves at low temperatures for Sims and Gladman's material.

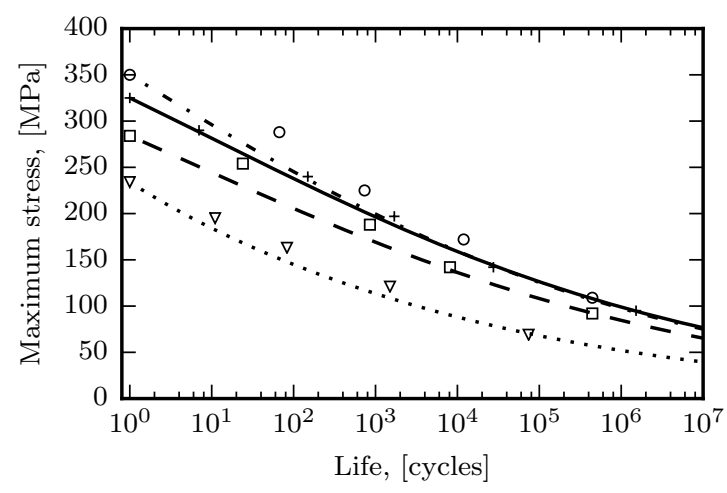

$$
\begin{array}{|cl|}
\hline \circ & -20^{\circ} \mathrm{C} \text { validation data } \\
-\cdots & -20^{\circ} \mathrm{C} \text { predicted }(\alpha=0.499) \\
+ & 23^{\circ} \mathrm{C} \text { reference data } \\
\hline & 23^{\circ} \mathrm{C} \text { reference }(\alpha=0.418) \\
\square & 60^{\circ} \mathrm{C} \text { validation data } \\
- & -60^{\circ} \mathrm{C} \text { predicted }(\alpha=0.438) \\
\nabla & 100^{\circ} \mathrm{C} \text { validation data } \\
\cdots & 100^{\circ} \mathrm{C} \text { predicted }(\alpha=0.774)
\end{array}
$$

Figure 11: Predicted $S-N$ curves at high temperatures for Sims and Gladman's material. 
The generally good fit provided by the model validates the predictive ability of the proposed methodology for woven glass-epoxy composite loaded in tension along the fibre direction. It is also shown that in the case of materials exhibiting multiple structural transitions, minimal additional experimental efforts allow for the prediction of fatigue behaviour over very broad temperature ranges.

\subsection{General discussion}

As stated earlier, many models are available for describing the fatigue behaviour of composites. However, these are not all equal in terms of quality of fit. Although measures for goodness of fit are seldom provided in the fatigue literature, some documents do include $r^{2}$ values for $S-N$ curves or CLDs (which can be seen as an extension of the $S-N$ formulation over multiple load ratios $R$ ). For example, the 57 fits found in Boisseau et al.[52], Corum et al.[53] and Vassilopoulos et al.[54] have coefficients of determination in the range of $0.15 \leq r^{2} \leq 0.99$ (mean $=0.74$, median $=0.83$, standard deviation $=0.20$ ). From these results, it is seen that because of the inherent variability in the durability of composites subject to fatigue and because of small datasets usually used for fatigue research, relatively low coefficients of determinations may be expected.

In the current work, the model by Epaarachchi and Clausen was selected as a baseline for further development. With $r^{2} \geq 0.999$ obtained for two out of the three baseline conditions and $r^{2}=0.873$ for the third, the goodness of fit for the baseline conditions compares favourably with results from the literature.

Also, based on the results summarized in Table 2, 4 and 5 the use of measured or modelled strength provides estimates of the fatigue model parameters that are very close. Values of $r^{2}$ for models based on measured and modelled strengths are mostly within a few tenths of a percent, with the worst difference being $1.6 \%$ for the fit at $-150^{\circ} \mathrm{C}$ on $\mathrm{Sims}$ and Gladman's data. Moreover, 12 out of the 14 curves fitted by regression using $\beta_{0}$ and the static strength model from equation 5 have a $r^{2}>0.95$ and 10 out of 14 even give $r^{2}>0.98$. Even the worst value of $r^{2}$ obtained, at 0.873 for WESNet's baseline condition, is above both the mean and median from the selected literature. It thus appears that the model by Epaarachchi and Clausen in conjunction with the proposed model for $S_{u}(T)$ is well suited to describe the behaviour of glass-polymer composites under tensile fatigue loading at any temperature.

Knowing that the baseline $S-N$ curves are in good agreement with experiments, the fit of predicted curves can be evaluated. Nine out of the ten $S-N$ curves predicted at various temperatures have $r^{2}>0.85$ and the lowest fit obtained is $r^{2}=0.737$ for woven laminates at $-150^{\circ} \mathrm{C}$. Thus, the goodness of fit for the proposed model also compares favourably with results from the literature and offers predictions that are at least as good as the average model from the literature which would have been fitted a posteriori to the data.

It is worth noting that predicted curves appear mostly conservative in their low-cycle fatigue life assessments. However, the prediction for the woven laminate at $-150^{\circ} \mathrm{C}$ is definitely biased towards longer lives in the high-cycle fatigue regime (Figure 10). Comparison of $\beta$ between the two fits on Sims and Gladman's data as well as the behaviour of the curve 
at $-150^{\circ} \mathrm{C}$ suggest that as the temperature goes down, the value $\beta$ could be expected to increase. This would be an indication that as the temperature is lowered, the difference between low-cycle and high-cycle fatigue behaviour gets more important.

The applicability of the proposed scheme is also corroborated by a comparison of $r_{\text {reg }}^{2}$ and $r_{\text {model }}^{2}$. For most predicted curves, the fit is only slightly worse than that of the best fit obtained by regression on the data. Unexpectedly, it appears that predictions at low temperatures may be somewhat weaker than those for high temperatures, although still quite satisfying. This might be attributed to changes in failure modes or to shrinkage stresses effectively altering the fatigue stress ratio, two phenomenons that are not accounted for in the model.

As the value of $r^{2}$ alone may not be a sufficient indication of a model quality of fit, a plot of measured versus predicted lives for all test conditions is provided in Figure 12. In such a figure, points falling on the $45^{\circ}$ line represent a perfect prediction from the model and the farther away from this diagonal a point is, the less accurate the prediction. In Figure 12, it is seen that of the 160 points used in the analysis, the model predicts a fatigue life within \pm 1 decade of the measured one at a rate of $99.4 \%$ and within \pm 0.5 decade for $96.9 \%$ of the data. An accuracy within \pm 0.25 decade is even reached for $73.1 \%$ of the data. Considering the important scatter of fatigue data, such a level of accuracy in the prediction is very good.

The fit on results by Sims and Gladman[1] for which exact transition temperatures were unknown also suggest that both $T_{0}$ and $\Theta$ to be used in equation 6 can be chosen arbitrarily within a structural transition and the model should perform adequately. Thus, although a transition temperature such as $T_{g}$ seems like a natural candidate for $\Theta$, it is not a requirement of the model.

Finally, Eftekhari and Fatemi[16, 22] have used the model by Epaarachchi and Clausen[13] - which is also the basis of the current work - in order to predict the effects of frequency and temperature on several neat, talc filled or short glass fibres reinforced thermoplastics. In these papers, they found that Epaarachchi and Clausen's model provides a good fit on experimental results and used a Larson-Miller type relationship to account for viscoelastic effects that were present at higher temperatures or lower load rates. A notable result from their research is that a single parameter set of $\alpha=0.135$ and $\beta=0.2$ was reported to provide a good fit for all the materials they tested. It is interesting to note that the values of $\beta$ obtained in the current paper are close to that of Eftekhari and Fatemi. This suggests that in the absence of other information, a value of $\beta=0.2$ might be useful for preliminary analysis or as a starting point in the optimization of model parameters. On the other hand, the use of a constant $\alpha$ does not appear to be a valid approach for long glass fibre reinforced thermosets as studied in the current paper. This is based on the fact that for all cases investigated here, $\alpha$ is shown to vary by more that $50 \%$ within a single transition region. Therefore, using a constant $\alpha$ would result in the use of an arbitrary value of the parameter (e.g. that from room temperature or an average over an arbitrarily chosen temperature range). For example, using the room temperature value of $\alpha$ for modelling the behaviour of Upwind's or Sims and Gladman's materials respectively reduces the resulting $r^{2}$ from 0.934 to 0.719 and from 0.982 to 0.652 . Such reductions in the quality of fit are strong arguments against the use of a constant $\alpha$ in the case of long fibres reinforced thermosets, 


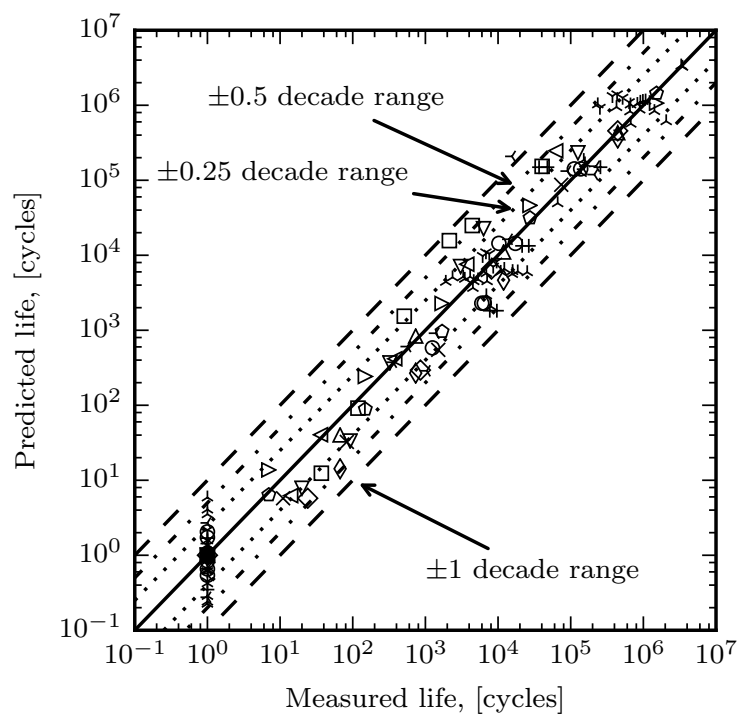

\begin{tabular}{|c|c|c|c|}
\hline 0 & WESNet $-40^{\circ} \mathrm{C}$ & $\triangleleft$ & $\mathrm{S} \& \mathrm{G}$ LTT $-60^{\circ} \mathrm{C}$ \\
\hline+ & WESNet $23^{\circ} \mathrm{C}$ & $\Delta$ & $\mathrm{S} \& \mathrm{G} \mathrm{LTT}-20^{\circ} \mathrm{C}$ \\
\hline Y & Upwind $-40^{\circ} \mathrm{C}$ & $\triangleright$ & $\mathrm{S} \& \mathrm{G} \operatorname{LTT} 23^{\circ} \mathrm{C}$ \\
\hline$\curlywedge$ & Upwind $23^{\circ} \mathrm{C}$ & $\diamond$ & $\mathrm{S} \& \mathrm{G} \mathrm{HTT}-20^{\circ} \mathrm{C}$ \\
\hline - & Upwind $60^{\circ} \mathrm{C}$ & ○ & $\mathrm{S} \& \mathrm{G}$ HTT $23^{\circ} \mathrm{C}$ \\
\hline$\square$ & $\mathrm{S} \& \mathrm{G}$ LTT $-150^{\circ} \mathrm{C}$ & $\diamond$ & $\mathrm{S} \& \mathrm{G}$ HTT $60^{\circ} \mathrm{C}$ \\
\hline$\nabla$ & $\mathrm{S} \& \mathrm{G}$ LTT $-100^{\circ} \mathrm{C}$ & $x$ & $\mathrm{~S} \& \mathrm{G}$ HTT $100^{\circ} \mathrm{C}$ \\
\hline
\end{tabular}

Figure 12: Measured versus predicted life diagram (S\&G LTT and S\&G HTT stand for Sims and Gladman low temperature transition and high temperature transition fits respectively). 
except as a very crude preliminary estimate.

\subsection{Statistical considerations}

Variability is an inherent property of the fatigue process in composites, thus the statistical treatment of fatigue data is of paramount importance. It is often the case with strength degradation fatigue models to assume a distribution of $S_{u}$ and to relate the expected fatigue life to this distribution. This is done by finding the inverse function of the life $N$ as a function of $S_{u}$ and then obtaining the fatigue life distribution through a change of variable in the SF or CDF of $S_{u}$. Description of such a procedure is given in the work of Yang and Liu[55] or Sendeckyj[27].

However, the model by Epaarachchi and Clausen[13] — which is the basis of the current paper - happens to be of a high order and is thus not invertible analytically. Nevertheless, since equation 4 is an increasing function of $S_{u}$ over the range of interest $(N>1$ and $\sigma_{\max } \leq S_{u}$ ), it has a unique inverse and the problem can be solved numerically. A general algorithm for obtaining the life $N$ for a given maximum cyclic load $\sigma_{\max }$ and probability of survival is shown in Figure 13. A probabilistic stress-life $(P-S-N)$ fatigue diagram can then be created by iterating the algorithm over a range of $\sigma_{\max }$.

In the current work, the distribution of $S_{u}$ was assumed to be normal and the $S-N$ curve was obtained with a least-square linear regression. The normal distribution was used for the sake of simplicity and because some data from the literature were only available as normal distribution means and standard deviations. Moreover, most sample sizes were too small to provide unbiased estimate of Weibull distribution's parameters.

A Python 2.7.6 script was used to numerically solve the inversion problem. The interp1d method from the scipy.interpolate module (scipy 0.17 ) was used to invert the $N\left(S_{u}\right)$ relationship and the cdf method of the norm function from the scipy. stats module was used to recreate the transformed CDF. The method is applied to the Upwind reference data at $23^{\circ} \mathrm{C}$ to demonstrate its functionality and the results are shown in Figure 14. The baseline $S-N$ curve as well as those at $95 \%$ and $99 \%$ probability of survival are shown. Estimates at $50 \%$ survival are also shown to demonstrate that they are equivalent to the baseline curve.

For establishing a $P-S-N$ curve at other temperatures, one would only need to use parameters from the distribution of $S_{u}$ at the desired temperature and the predicted fatigue model parameters (instead of running the linear regression). With this approach, it is possible to evaluate the $S-N$ curve at any probability of survival and for any temperature given that the static life distribution parameters are known at those temperatures. However, the work of Christensen and Myiano[56] demonstrated both analytically and experimentally that scatter in fatigue life should not change with temperature. One could then estimate the fatigue life at any temperature and for any percentile of survival using the reference condition static strength distribution if no other information is available.

Finally, despite the fact that a constant variance normal distribution was used to model $S_{u}$ and to obtain fatigue model parameters through linear regression, this distribution might not provide the best description of $S_{u}$ and fatigue scatter. Although it is adequate in the 


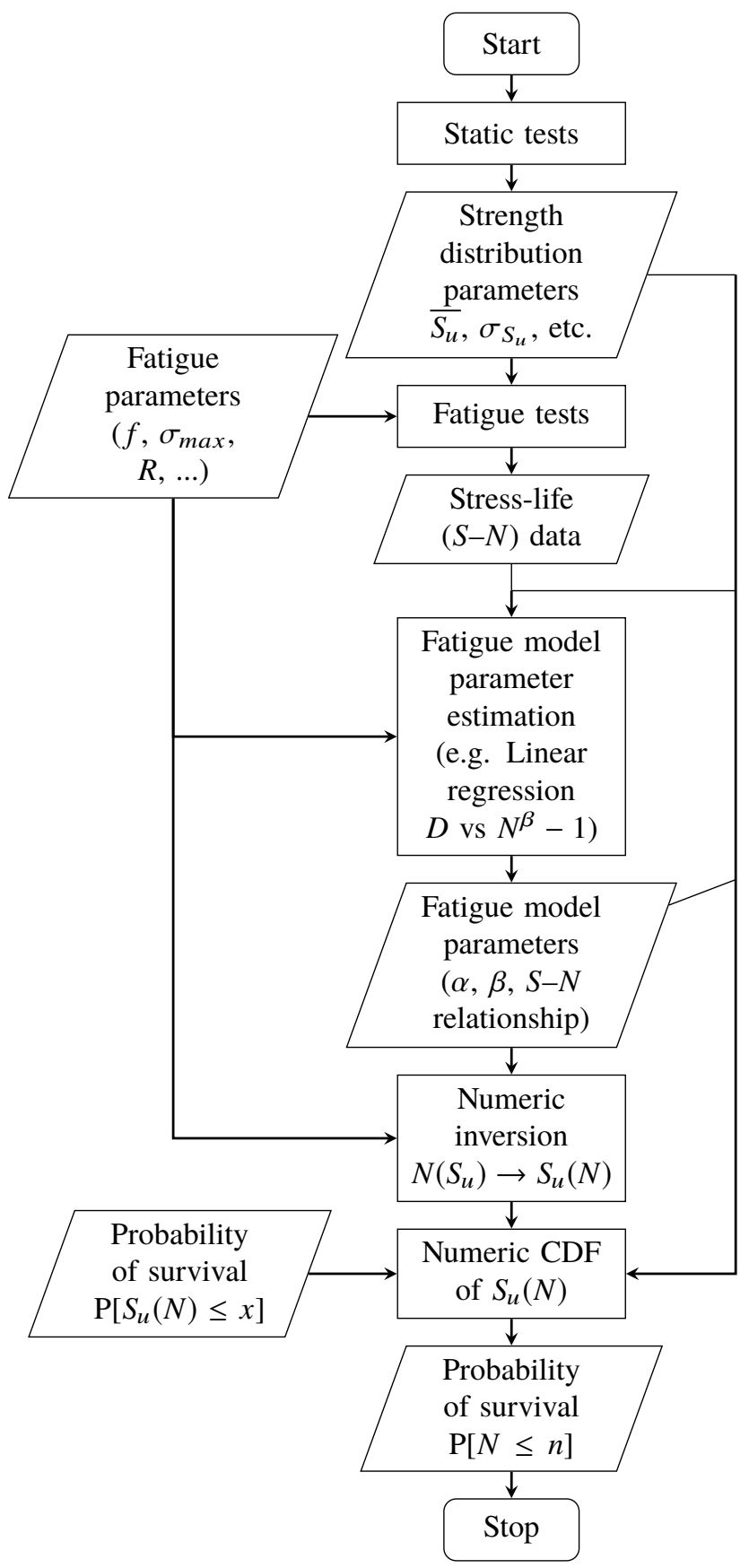

Figure 13: Numerical solution algorithm. 


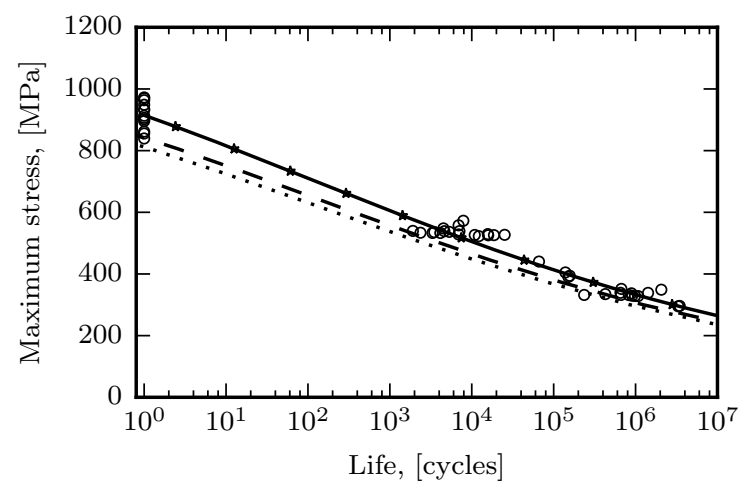

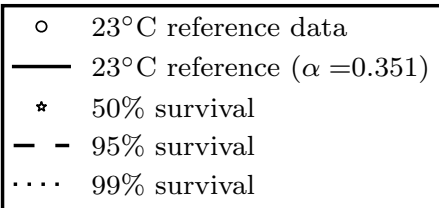

Figure 14: $P-S-N$ curves for $U p w i n d$ 's material at $23^{\circ} \mathrm{C}$

current research context, applications where a given reliability is targeted would require validation of the distribution choice (e.g. log-Normal or Weibull) and analysis with the associated statistics on larger samples.

\section{Conclusions}

Prediction of fatigue life of composite materials has challenged material scientists for decades. Part of the difficulty lies in the combination of conflicting requirements of versatility, often translating into complex models, and that of minimal experimental efforts in order to determine model parameters. Although major advances have been made, challenges such as that of accounting for the influence of environmental factors on fatigue life remain.

The current work aims at providing a model for predicting fatigue life of glass fibre reinforced polymer composites loaded in tension along the fibre direction at any temperature, while requiring only minimal experimental efforts. The procedure is based on two empirical formulations respectively describing the evolution of $S_{u}$ and of a single fatigue model parameter with temperature. The experimental requirements for obtaining all of the parameters required by the method are limited to tensile strength tests at a minimum of four temperatures and fatigue data at one temperature.

It was shown that the proposed static strength model provides a very good description of that material property within a single structural transition (e.g. the glass transition) for the four materials on which the model was validated. Application of the fatigue model to results from three earlier independent research projects showed that the predicted $S-N$ curves are in good to excellent agreement with experiments over a range of more than $100^{\circ} \mathrm{C}$. It was 
also shown that for material exhibiting multiple structural transitions, the model could be applied separately within each transition and provide good results, at the expense of requiring additional fatigue data at one temperature within each transition. A method for obtaining probabilistic fatigue life estimates based on the static strength distribution is also provided.

However, as mentioned earlier, versatility is a desirable characteristic for a fatigue model. In this regard, the proposed model would still need to be validated for composites using different reinforcement materials and matrix systems. Moreover, it is likely that further adjustments would be required to generalize the model to other fibre orientations. Nonetheless, it is believed that the relative simplicity of the proposed method combined with its ability to predict fatigue life over a wide range of temperatures with minimal experimental efforts make it particularly attractive.

\section{Acknowledgements}

The authors want to thank the Knowledge Centre Wind turbine Materials and Constructions (WMC - www.wmc.eu) for allowing Laurent Cormier to participate in the Upwind programme as a guest researcher under the supervision of Dr. Rogier Nijssen and for the resulting contribution to this research. Thanks also go to El Mostapha Frih for his valuable insight on statistical matters.

\section{Funding}

Natural Sciences and Engineering Research Council of Canada - Wind Energy Strategic Network WESNet [NETGP 340847-06]; Natural Sciences and Engineering Research Council of Canada - Doctoral grant program [ES D3-379032-2009]

\section{Declaration of conflicting of interests}

The authors declare that there is no conflict of interest.

\section{References}

[1] Sims GD and Gladman DG. A framework for specifing the fatigue performance of glass fibre reinforced plastics. Technical Report NPL Report DMA (A) 59, National Physical Laboratory, 1982.

[2] Bureau MN and Denault J. Fatigue resistance of continuous glass fiber/polypropylene composites: Temperature dependance. Polymer Composites 2004; 25: 622-629. 
[3] Brassard D. Étude des effets du climat nordique sur la durée de vie en fatigue en tension des composites unidirectionnels de fibres de verre et d'époxy. Master's Thesis, École de technologie supérieure, Montréal, 2014.

[4] Cormier L, Joncas S and Nijssen R. Effects of low temperature on the mechanical properties of glass fibre-epoxy composites: Static tension, compression, $R=0.1$ and $R=-1$ fatigue of $\pm 45^{\circ}$ laminates. Wind Energy 2016; 19(6): 1023-1041. DOI:10.1002/we.1880.

[5] Tang HC, Nguyen T, Chuang TJ et al. Temperature effects on fatigue of polymer composites. In Hui D (ed.) Composites Engineering, 7th Annual International Conference. ICCE/7. Composites Engineering and College of Engineering, University of New Orleans., pp. 861-862.

[6] Rotem A and Nelson H. Fatigue behavior of graphite-epoxy laminates at elevated temperatures. In Lauraitis KN (ed.) Fatigue of Fibrous Composite Materials. ASTM STP 723, Philadelphia: American Society for Testing and Materials, pp. 152-173.

[7] Mivehchi H and Varvani-Farahani A. Erratum to: Temperature dependence of stressfatigue life data of FRP composites. Mechanics of Composite Materials 2011; 47(3): 369-376. DOI:10.1007/s11029-011-9215-9.

[8] Sutherland HJ. A summary of the fatigue properties of wind turbine materials. Wind Energy 2000; 3(1): 1-34. DOI:10.1002/1099-1824(200001/03)3:1<1::AID-WE28> 3.0.CO;2-2.

[9] Miyano Y, Nakada M, Kudoh H et al. Prediction of tensile fatigue life under temperature environment for unidirectional CFRP. Advanced Composite Materials 1999; 8(3): 235-246. DOI:10.1163/156855199X00236.

[10] Miyano Y, Nakada M and Cai H. Formulation of long-term creep and fatigue strengths of polymer composites based on accelerated testing methodology. Journal of Composite Materials 2008; 42(18): 1897-1919. DOI:10.1177/0021998308093913.

[11] Nakada M and Miyano Y. Advanced accelerated testing methodology for long-term life prediction of CFRP laminates. Journal of Composite Materials 2013; DOI:10.1177/0021998313515019. URL \url\{http://jcm.sagepub. com/content/early/2013/12/10/0021998313515019. full.pdf+html\}. DOI:10.1177/0021998313515019, http://jcm.sagepub.com/content/early/ 2013/12/10/0021998313515019. full.pdf+html.

[12] Reifsnider K, Case $\mathrm{S}$ and Duthoit J. The mechanics of composite strength evolution. Composites Science and Technology 2000; 60(12-13): 2539-2546. DOI:http://dx.doi. org/10.1016/S0266-3538(00)00047-6. 
[13] Epaarachchi JA and Clausen PD. An empirical model for fatigue behavior prediction of glass fibre-reinforced plastic composites for various stress ratios and test frequencies. Composites Part A: Applied Science and Manufacturing 2003; 34(4): 313 - 326. DOI:http://dx.doi.org/10.1016/S1359-835X(03)00052-6.

[14] Mandell JF and Meier U. Effects of stress ratio, frequency and loading time on the tensile fatigue of glass-reinforced epoxy, long-term behaviour of composites. In O'Brien T (ed.) Long-Term Behavior of Composites. ASTM STP 813, Philadelphia: American Society for Testing Material, pp. 55-77.

[15] Hahn HT and Turkgenc O. The effect of loading parameters on fatigue of composite laminates: Part IV information systems. resreport DOT/FAA/AR-00/48, U.S. Department of Transportation, Federal Aviation Administration, Office of Aviation Research, 2000 .

[16] Eftekhari $\mathrm{M}$ and Fatemi A. On the strengthening effect of increasing cycling frequency on fatigue behavior of some polymers and their composites: Experiments and modeling. International Journal of Fatigue 2016; 87: 153 - 166. DOI: http://dx.doi.org/10.1016/j.ijfatigue.2016.01.014.

[17] Sun CT and Chan WS. Frequency effect on the fatigue life of a laminated composite. In Tsai SW (ed.) Composite Materials :Testing and Design (Fifth Conference). ASTM STP 674, American Society for Testing and Materials, pp. 418-430.

[18] Saff CR. Effect of load frequency and lay-up on fatigue life of composites. In O'Brien TK (ed.) Long-Term Behavior of Composites. ASTM STP 813, Philadelphia: American Society for Testing and Materials, pp. 78-91.

[19] Kharrazi MR and Sarkani S. Frequency-dependent fatigue damage accumulation in fiber-reinforced plastics. Journal of Composite Materials 2001; 35(21): 1924-1953. DOI:10.1177/002199801772661443.

[20] Hahn HT and Kim RY. Fatigue behavior of composite laminate. Journal of Composite Materials 1976; 10(2): 156-180. DOI:10.1177/002199837601000205.

[21] Crowther M, Wyatt R and Phillips M. Creep-fatigue interactions in glass fibre/polyester composites. Composites Science and Technology 1989; 36: 191-210.

[22] Eftekhari $M$ and Fatemi A. Fatigue behaviour and modelling of talc-filled and short glass fibre reinforced thermoplastics, including temperature and mean stress effects. Fatigue \& Fracture of Engineering Materials \& Structures 2016; DOI:10.1111/ffe.12497. URL \url\{http://dx. doi .org/10.1111/ffe.12497\}. DOI:10.1111/ffe.12497.

[23] Kujawski D and Ellyin F. Rate/frequency-dependent behaviour of fibreglass/epoxy laminates in tensile and cyclic loading. Composites 1995; 26(10): 719-723. 
[24] Guedes R. Durability of polymer matrix composites: Viscoelastic effect on static and fatigue loading. Composites Science and Technology 2007; 67(11-12): 2574-2583. DOI:http://dx.doi.org/10.1016/j.compscitech.2006.12.004.

[25] Sullivan JL. Creep and physical aging of composites. Composite Science and Technology 1990; 39(3): 207-232.

[26] Brinson LC and Gates TS. Effects of physical aging on long term creep of polymers and polymer matrix composites. International Journal of Solids and Structures 1995; 32(6): 827 - 846. DOI:http://dx.doi.org/10.1016/0020-7683(94)00163-Q.

[27] Sendeckyj GP. Chapter 10 - life prediction for resin-matrix composite materials. In Reifsnider K (ed.) Fatigue of Composite Materials, Composite Materials Series, volume 4. Elsevier, 1991. pp. 431 - 483. DOI:http://dx.doi.org/10.1016/ B978-0-444-70507-5.50014-7.

[28] Degrieck J and Van Paepegem W. Fatigue damage modeling of fibre-reinforced composite materials: Review. Applied Mechanics Reviews 2001; 54(4): 279-300. DOI:10.1115/1.1381395.

[29] Nijssen R. Fatigue Life Prediction and Strength Degradation of Wind Turbine Rotor Blades. PhD Thesis, Delft University, 2006.

[30] Sayyidmousavi A, Bougherara H and Fawaz Z. The role of viscoelasticity on the fatigue of angle-ply polymer matrix composites at high and room temperatures- a micromechanical approach. Applied Composite Materials 2014; 22(3): 307-321. DOI:10.1007/s10443-014-9409-0.

[31] Chamis CC. Simplified composite micromechanics equations for hygral, thermal and mechanical properties. Technical Report NAS 1.15:83320, NASA Glenn Research Center, 1983.

[32] Christensen RM. A critical evaluation for a class of micro-mechanics models. Journal of the Mechanics and Physics of Solids 1990; 38(3): 379 - 404. DOI:http://dx.doi. org/10.1016/0022-5096(90)90005-O.

[33] Cormier L and Joncas S. Effects of cold temperature, moisture and freeze-thaw cycles on the mechanical properties of unidirectional glass fiber-epoxy composites. In 51st AIAA / ASME / ASCE / AHS / ASC Structures, Structural Dynamics and Materials Conference. AIAA-2010-2823, Orlando, FL, United-States: AIAA.

[34] Mahieux C, Reifsnider K and Case S. Property modeling across transition temperatures in PMC's: Part I. tensile properties. Applied Composite Materials 2001; 8(4): 217234. DOI:10.1023/A:1011282704357. 
[35] Cao S, Wang $\mathrm{X}$ and $\mathrm{Wu} \mathrm{Z}$. Evaluation and prediction of temperature-dependent tensile strength of unidirectional carbon fiber-reinforced polymer composites. Journal of Reinforced Plastics and Composites 2011; 30(9): 799-807. DOI:10.1177/ 0731684411411002.

[36] Nijssen R and Cormier L. Experiments and modelling of influence and interaction of temperature and frequency on fatigue life. Technical Report Upwind Deliverable D 3.1.8/WMC-2010-94, Knowledge Centre Wind turbine Materials and Constructions, 2011.

[37] Cormier L and Nijssen R. Temperature and frequency effects on the fatigue properties of unidirectional glass fiber-epoxy composites. In 53rd AIAA / ASME / ASCE / AHS / ASC Structures, Structural Dynamics and Materials Conference. AIAA-2012-1574, Honolulu, HI, United-States: AIAA.

[38] Toth JM, Bailey WJ and Boyce DA. Fiberglass epoxy laminate fatigue properties at 300 and 20 K. In Stephens RI (ed.) Fatigue at low temperature. ASTM STP 857, Philadelphia: American Society for Testing and Materials, pp. 163-172.

[39] Kawai M, Matsuda Y and Yoshimura R. A general method for predicting temperaturedependent anisomorphic constant fatigue life diagram for a woven fabric carbon/epoxy laminate. Composites Part A: Applied Science and Manufacturing 2012; 43(6): 915 - 925. DOI:http://dx.doi.org/10.1016/j.compositesa.2012.01.025.

[40] Dutta PK. Tensile strength of unidirectional fiber composites at low temperatures. In Japan-U.S. Conference on Composite Materials. pp. 782-792.

[41] Mahieux C and Reifsnider K. Property modeling across transition temperatures in polymers: A robust stiffness-temperature model. Polymer 2001; 42(7): 3281 - 3291.

[42] Correia JR, Gomes MM, Pires JM et al. Mechanical behaviour of pultruded glass fibre reinforced polymer composites at elevated temperature: Experiments and model assessment. Composite Structures 2013; 98: 303 - 313. DOI:http://dx.doi.org/10. 1016/j.compstruct.2012.10.051.

[43] Gibson AG, Wu YS, Evans JT et al. Laminate theory analysis of composites under load in fire. Journal of Composite Materials 2006; 40(7): 639-658. DOI:10.1177/ 0021998305055543.

[44] Gompertz B. On the nature of the function expressive of the law of human mortality, and on a new mode of determining the value of life contingencies. In Philosophical Transactions of the Royal Society of London, volume 115. pp. 513-583.

[45] Garg ML, Raja Rao B and Redmond CK. Maximum-likelihood estimation of the parameters of the Gompertz survival function. Journal of the Royal Statistical Society: Series C (Applied Statistics) 1970; 19(2): 152-159. 
[46] Adams RD and Singh MM. Low temperature transitions in fibre reinforced polymers. Composites Part A: Applied Science and Manufacturing 2001; 32(6): 797-814. DOI: 10.1016/S1359-835X(00)00185-8.

[47] Robert M and Benmokrane B. Behavior of GFRP reinforcing bars subjected to extreme temperatures. Journal of Composites for Construction 2010; 14(4): 353-360. DOI: 10.1061/(ASCE)CC.1943-5614.0000092.

[48] Krause O. Testing frequency for dynamic tests. Technical Report OB_TC_N003_DLR, Deutsches Zentrum für Luft- und Raumfahrt, DLR, 2002. Optimat Blade Project.

[49] Krause $\mathrm{O}$ and Philippidis TP. General test specification. Technical Report OB_TC_R014 rev.005, Deutsches Zentrum f Ã¹/4r Luft- und Raumfahrt; DLR, 2005. Optimat Blade Project.

[50] Knowledge Center Wind turbine Materials and Constructions. Optidat fatigue of wind turbine materials database. Database, 2011. URL https://www. wmc. eu/optimatblades_optidat.php. https://www. wmc.eu/optimatblades \ _optidat.php. Visited 2017-05-30.

[51] ASTM subcommitee D3004. Standard Test Method for Tensile Properties of Polymer Matrix Composite Materials. Standard D 3039/D 3039M - 08, ASTM subcommitee D30.04 on Lamina and Laminate Test Methods, West Conshohocken, PA, 2008.

[52] Boisseau A, Davies P and Thiebaud F. Fatigue behaviour of glass fibre reinforced composites for ocean energy conversion systems. Applied Composite Materials 2012; 20(2): 145-155. DOI:10.1007/s10443-012-9260-0.

[53] Corum J, Battiste R, Liu K et al. Basic properties of reference crossply carbon-fiber composite. Technical Report ORNL/TM-2000/29, Oak Ridge National Laboratory, 2000 .

[54] Vassilopoulos AP, Manshadi BD and Keller T. Influence of the constant life diagram formulation on the fatigue life prediction of composite materials. International Journal of Fatigue 2010; 32(4): 659 - 669. DOI:http://dx.doi.org/10.1016/j.ijfatigue.2009.09. 008 .

[55] Yang J and Liu M. Residual strength degradation model and theory of periodic proof tests for graphite/epoxy laminates. Journal of Composite Materials 1977; 11(2): 176-203. DOI:10.1177/002199837701100205.

[56] Christensen R and Miyano Y. Stress intensity controlled kinetic crack growth and stress history dependent life prediction with statistical variability. International Journal of Fracture 2006; 137(1-4): 77-87. DOI:10.1007/s10704-005-9062-6. 